\title{
Emerging Digital Generations? Impacts of Child Digital Use on Mental and Socioemotional Well-Being across Two Cohorts in Ireland, 2007-2018
}

\author{
Melissa Bohnert ${ }^{1}$ (D) Pablo Gracia ${ }^{1}$ \\ Accepted: 15 August 2020 / Published online: 31 August 2020 \\ (C) The Author(s) 2020
}

\begin{abstract}
Despite the growing body of literature on how digital technologies impact child wellbeing, previous research has provided little evidence on recent digital trends. This paper examines the patterns and effects of digital use on child socioemotional well-being across two cohorts of children grown up ten years apart during the digital age': the 1998 cohort (interviewed in 2007/08) and the 2008 cohort (interviewed in 2017/18). Multivariate linear regression models were conducted for these two cohorts from the Growing Up in Ireland (GUI) study, a multicohort longitudinal study with rich comparable data on a large sample of 9-year olds $(N=13,203)$. Results show that (i) in $2017 / 18$ children were more active in digital devices and social media, while in 2007/2008 children spent more time watching TV and adopted less diversified forms of media engagement; (ii) spending more than 3 daily hours on TV/digital activities was associated with significant declines in child socioemotional well-being, while such effects were stronger in 2017/18 than in 2007/08; (iii) media engagement (but not other forms of digital engagement) was associated with moderate declines in socioemotional well-being, both in 2007/08 and in 2017/18; (iv) while children's media and digital engagement differed by the child gender and socioeconomic background, none of these variables moderated the effects of digital use on children's socioemotional well-being, neither in 2007/08 nor in 2017/18. Overall, the study reveals persistence, but also some important changes, in recent trends on children's digital use and its impact on socioemotional wellbeing in Ireland.
\end{abstract}

Keywords Digital use $\cdot$ Media $\cdot$ Child socioemotional wellbeing $\cdot$ Cohort effects $\cdot$ Ireland

Melissa Bohnert

bohnertm@tcd.ie

1 Department of Sociology, School of Social Sciences and Philosophy, Trinity College Dublin, College Green 1, Dublin Dublin 02, Ireland 


\section{Introduction}

Today's youth have unprecedented access to digital media and technologies, having grown up as 'digital natives.' Digital devices and activities, and how children engage with them, are constantly evolving. These recent rapid transformations in digitalization suggest that today's youth do not form a single coherent digital generation, with children's 'new' digital contexts differing remarkably from those of children in previous cohorts (Livingstone and Helsper 2007; Livingstone et al. 2018). Consequently, studying how recent digital changes can affect the well-being of children from the youngest generations is critical to understand childhood in our digital age.

Previous studies suggest that children born after 2008, so-called 'digitods', have patterns of digital engagement that differ significantly from those of children born a decade earlier (Holloway et al. 2015; Leathers et al. 2013). Digitods are the first cohort to grow up entirely after the launch of smartphones to the popular market, with most having grown up in households with access to portable touch-screen devices with enhanced computing power and mobility (Livingstone and Helsper 2007; Kucirnova and Sakr 2015). The new cohort of 'digitods' have parents who tend to be experienced digital users themselves and who often adopt 'new' digital parental mediation strategies to promote children's safe media use and digital literacy (Bennett et al. 2008; Brito et al. 2018). Yet, younger children are increasingly exposed to a multitude of digital technologies at a very early age (Mascheroni and Olafsson 2016), which may lead to potential well-being problems associated with excessive screen-time or nondevelopmentally appropriate media use. To date, however, very little is known on whether current children's digital engagement is affecting their well-being differently compared to previous generations. Our study addresses this critical question to further understand children's lives and well-being in contemporary societies.

This paper investigates whether children's patterns of digital use, and the effects of this usage on socioemotional well-being, differs across cohorts. Cohorts present a fundamental way to 'demarcate groups of individuals who experience historical periods that are suspected to produce unique outcomes not present in individuals from different periods of time' (Campbell and Pearlman 2013: 1698). By comparing different cohorts, scholars can ideally examine whether the association between specific variables (i.e., child digital use and well-being) differs between individuals who have been socialized at different socio-historical moments (Mannheim 1952; Yang 2008). Therefore, our cohort approach provides a nuanced understanding of temporal trends on how digitalization can affect child well-being (see Campbell et al. 2015).

We use data from a representative large-scale multi-cohort longitudinal survey from Ireland: the Growing Up in Ireland (GUI) study. The GUI allows us to ideally measure the role technology plays in children's lives by using comparable measures of children's digital use and socioemotional well-being at the age of 9 by contrasting two birth cohorts born ten years apart: the 1998 Cohort and 2008 Cohort. Our focus on middle childhood (9 years old) is relevant to research on child development, as this is a lifecourse stage in which children increasingly start to develop genuine and independent media and technology styles with key well-being consequences (Valkenburg and Piotrowski 2017). Our cohort approach on 9-year old children permits us to trace a sociohistorical account of 10-years difference across two cohorts. 
The paper makes two key contributions to the literature. First, our study is - to our knowledge - the first analysis of cohort changes on the effect of child digital use on well-being outcomes. Two studies with data from the US Panel Study of Income Dynamics addressed cohort changes in the associations between children's digital behaviors and other daily activities (Fomby et al. 2019; Goode et al. 2019). Using data from two cohorts of children aged 2-11 sampled in 1997 (born 1986-1995) and 20142016 (born 2003-2014), Goode et al. (2019) found more varied usage of digital technology and stronger negative associations between digital use and physical activity in the youngest cohort, compared to the older cohort. Likewise, Fomby et al. (2019) found increased digital time use and further displacement of physical activity across cohorts, while also finding significant associations of digital time use with play (in early childhood) and increased sleep (in middle childhood) in the younger cohort of 11 to 17-year-olds (born 1985-1991), compared to the older cohort (born 1997-2003). Yet, previous cohort studies did not assess the impact of digital use on specific wellbeing outcomes. Our study makes an important contribution by providing evidence on the persistence (or lack of it) in the impact of digital use on child socioemotional outcomes across two recent cohorts.

Second, our paper examines whether digital engagement has affected children's well-being differently across time by examining the moderating role of socioeconomic status (SES) and gender. Low-SES children were found to spend more time on screenbased activities, with or without parents, compared to high-SES children, while more privileged children tend to be socialized in family digital contexts that are likely to maximize their well-being opportunities and minimize developmental risks (Gracia and Garcia-Roman 2018; Nikken and Opree 2018). Also, boys were found to spend more time than girls on screen-based activities across different countries, while the effect of child digital engagement on well-being is gendered, with studies suggesting that boys' and girls' well-being might be harmed differently by the usage of digital devices (Barker 2009; Booker et al. 2015, 2018; Gracia et al. 2020; Jackson et al. 2008; Liff and Sheperd 2004; The Children's Society 2015). In our context of rapid digital innovation, changing gender roles and increasing socioeconomic inequalities, it is relevant to examine whether SES and gender are playing a role in moderating the impact of digital activities on child well-being across recent cohorts. In this sense, our study contributes to debates on the heterogeneous impact of digital technologies on child well-being across socioeconomic and demographic groups.

\section{Analytical Framework}

\subsection{Children's Digitalization in Ireland}

We start the analytical background by briefly situating our national case of study: Ireland. While our study does not compare Ireland with other countries, we can better contextualize our empirical study within the literature on digitalization and child wellbeing by situating the Irish case internationally.

Ireland presents an interesting case of study. In Ireland, internet and smartphone penetration is growing, but it has not reached the highest saturation rates of many Continental and Northern European countries. Data from the EU Kids Online Survey 
(2011) reported that 93\% of Irish children aged 9-16 have regular access to the Internet. The Net Children Go Mobile (2015) survey shows that 63\% of Irish children aged 9-16 use the Internet at least once a day, with $46 \%$ accessing the Internet primarily through their own smartphone (O’Neill and Dinh 2015). Both surveys found daily Internet use and average time spent online by Irish young people somewhat below average compared to other European countries (O’Neill et al. 2011; O’Neill and Dinh 2015).

The two Irish cohorts we are comparing in our study (one born in 1998; another born in 2008), not only differ in terms of their relative access to forms of digitalization, but also in how the 2008 economic recession has affected them (Cantillon et al. 2017). Children born in the late 1990s (1998 cohort) experienced a booming economy in Ireland during their early years, while the children of the Great recession (2008 cohort) have experienced higher risks of poverty and particularly pervasive levels of economic uncertainty (Reinhard et al. 2018).

The two Irish cohorts, in addition to these differing economic circumstances, are also characterized by differing social and cultural conditions. Social media in particular has facilitated changing social dynamics in the way children interact and network with others. For 'digitods', children's technology use shifted from focusing on education and passive entertainment to being intertwined with identities, social networks, and everyday experiences (Fomby et al. 2019). Additionally, this increased connectivity, networking, and potential for identity formation has coincided with a time of international political and cultural upheaval (e.g. 2016 US presidential election, Brexit) that has potentially generated new forms of media engagement that may be affecting the cultural and media socialisation of children from the younger cohort, compared to the older cohort.

To date, few studies have examined how child and adolescent digital media usage affects well-being in Ireland. The few studies in this field focus on academic outcomes, with findings being mixed (Casey et al. 2012; Dempsey et al. 2019). Additionally, while the EU Kids Online (2011) and Net Children Go Mobile (2015) have provided insights into how Irish children spend their time online, the data published are largely descriptive in nature, without showing how these patterns of digital use may be impacting key developmental outcomes like mental and socioemotional well-being. No study has, to the best of our knowledge, compared recent historical trends in the effects of digital engagement on child well-being. These important gaps strongly motivate our study with Irish data.

\subsection{Impacts of Children Digital Use on Socioemotional Well-Being}

Concerns over the potential effects of children's and adolescents' digital technology use on their well-being have been emerging since the 1990s. Early studies were important first glimpses of how emerging digital technologies can affect child wellbeing outcomes. Yet, these studies were conducted at a time in which children's digital and online engagement was 'generally still marginal and impacts were more difficult to discern' (Vilhelmson et al. 2018: 2901), leading to limited samples and highly biased findings (George et al. 2018). As access to digital technologies has widened dramatically and an ever-increasing majority of children found their way online, new research in this field has appeared.

Recent studies on child digital engagement and well-being have provided results that are often mixed and inconclusive (Castellacci and Tveito 2018; Orben and Przybylski 
2019a, b; Stiglic and Viner 2019). Considerable evidence has suggested a negative relationship between digital technology usage and child and adolescent well-being (Fioravanti et al. 2012; Hwang et al. 2009; Kelly et al. 2018; Kross et al. 2013; Pantic et al. 2012; Parkes et al. 2013; Liu et al. 2016; Twenge et al. 2018; van den Eijnden et al. 2008). These studies indicated that children's increased usage of digital technologies is associated with increased depressive symptoms, increased difficulties in psychosocial adjustment, reduced self-esteem/self-concept, and increased social isolation through displacement of in-person socializing activities. Such studies reporting negative associations have tended to capture large amounts of public and political attention on children's media use. However, other studies find a positive relationship between child well-being and time spent on digital technologies (Berryman et al. 2018; Davis 2012; Gross 2009; Selfhout et al. 2009). These studies tend to indicate that children's use of digital technologies foster increased social support, widened social networks, reduced social anxiety, and reduced social isolation (Best et al. 2014). And still, many studies have found no significant association at all (Babic et al. 2017; Baker and White 2010; Bruggeman et al. 2019; Leung 2014; Williams and Merten 2008).

Studies increasingly indicate a small (when any) association between children's time spent on digital technologies and socioemotional well-being. When significant (positive or negative) associations are found, they tend to be small. For example, Orben and Przybylski's (2019b) study with three large-scale datasets found statistically significant associations between children's digital technology use and well-being problems, but effects were smaller than those observed for apparently neutral activities (i.e., regularly eating potatoes) (Orben and Przybylski 2019b). This evidence calls for research on the specific type and context of digital activities to understand the mechanisms by which child digital engagement can impact socioemotional well-being.

Previous studies on the impact of technologies on child well-being tended to omit a clear distinction between quantity and quality of digital engagement (Blair et al. 2015). As digital media and technologies have become more complex and ubiquitous, there is an ever-increasing number of disparate activities that children can participate in through digital technologies. For example, today children can watch TV, access huge numbers of games and apps or socialize with friends, which are likely to have differing impacts on well-being. Therefore, rather than studying digital use as a 'singular black box', researchers are increasingly utilizing more nuanced measures that can account for both quality and quantity of digital use (Livingstone et al. 2018). Our paper follows this approach by including both the quantity (amount of time) and quality (specific activities) of children's digital use and its impact on socioemotional well-being.

Drawing on the time displacement hypothesis, we argue that high quantities of digital use replace more enriching face-to-face activities, especially at extreme levels of screen-time (Kross et al. 2013; George et al. 2018). Following Przybylski and Weinstein (2017), we do not hypothesize a linear negative relationship across all levels of digital use. Thus, we expect negative effects of screen-based time (digital or TV) on socioemotional well-being only for children reporting the highest levels of digital screen-time, compared to their peers. As for the quality of digital engagement, some recent evidence suggests that informational and educational activities increase socioemotional and psychosocial well-being, as they are relatively low-risk and highopportunity digital activities (Camerini et al. 2018; Livingstone et al. 2018). By contrast, social, entertainment, and media activities might be more high-risk and low- 
opportunity activities when it comes to child socioemotional well-being, as they have been found to be associated with distraction (Mascheroni and Olafsson 2016), poor self-concept (Kelly et al. 2018; van der Aa et al. 2009; Verduyn et al. 2017), cyberbullying (Fahy et al. 2016), and depressive symptoms (Lemola et al. 2015; George et al. 2018).

Hypothesis 1a: High levels of children's screen-time engagement (digital or TV) are associated with higher socioemotional problems.

Hypothesis 1b: Child engagement in social and entertainment media digital activities is associated with higher socioemotional problems, while informational and educational digital activities are associated with lower socioemotional problems.

\subsection{Heterogeneity by Socioeconomic Status and Gender}

Research shows that demographic and socioeconomic factors influence children's digital usage and their associated outcomes. High-SES parents are able to impart digital skills and competencies to their children that allow them to stay ahead (Nikken and Opree 2018). Across countries, children in high-SES backgrounds are socialized in ways that lead them to reduce their amounts of time in screen-based activities, compared to low-SES children (Gracia et al. 2019). Thus, high-SES children grow up in families that grant privileged social, cultural and digital capitals to wield in mitigating risks and maximizing opportunities intrinsic to technology use (Livingstone and Helsper 2010). Hence, the negative effects of child digital use on socioemotional well-being might be weaker for high-SES children than for low-SES children.

Gender is another key moderator considered in this literature. Boys spend more time than girls on digital activities, focusing especially on gaming, while girls engage relatively more on social digital activities (Ortega et al. 2010; Wight et al. 2009; Brooks et al. 2016; Gracia et al. 2020). Boys, particularly at high levels of digital usage, were found to show greater risks of aggressive behavior and depressive symptoms than girls (Ortega et al. 2010; Booker et al. 2018). If boys are at higher risk of experiencing psychosocial problems associated with digital engagement (i.e., hyperactivity, aggressiveness), and are more likely to spend 'too much' time in front of screens, compared to girls, one could expect that boys' socioemotional well-being is disproportionally harmed by digital engagement.

Hypothesis 2a: The hypothesized association between child digital use and higher socioemotional problems affects boys more than girls.

Hypothesis 2b: The hypothesized association between child digital use and higher socioemotional problems affects low-SES families more than high-SES families.

\subsection{Digital Generations and Cohort Effects}

Birth cohorts are made up of individuals born in the same year, with those within the cohort moving through the life course simultaneously and encountering the same socio- 
historical events at the same ages (Gentile et al. 2013; Yang 2008). We conceptualize cohorts as 'age cohorts that come to have social significance by virtue of constituting itself within a social, cultural, and political identity' (Fortunati et al. 2019). Increasingly, many researchers have questioned the cultural and academic tendency to group all of today's youth into a single coherent digital generation (e.g. 'Gen Z') (see Livingstone and Helsper 2007). Our study compares the 1998 cohort with the 2008 cohort in Ireland by acknowledging the important differences in the digital, economic and cultural experiences between these two cohorts.

To compare our two Irish cohorts of study, one born 1998 and the other in 2008, we need to recall the rapid digital changes that have occurred in the world in the last decade. The early 2010s marked a shift in technological innovation with the invention and rapid adoption of smartphones, with other highly portable and interactive technologies like tablets following soon after. Compared to children born in the late 1990s, children born around 2010 have been socialized since birth with the power, portability and ubiquity of newer 'digi-tod' technologies and digital platforms (Kucirnova and Sakr 2015; Livingstone and Helsper 2007; Mascheroni and Cuman 2014). Children born around 2010, compared to those born one decade earlier, are also more likely to be socialized in digitally rich family contexts, where parents are experienced digital users who adopt active digital parenting techniques (Bennett et al. 2008; Brito et al. 2018). However, the existing body of research has - to our knowledge - not provided evidence on whether the effect of digital use on child well-being outcomes has changed over the last decade.

Our hypotheses on cohort changes in digital use and socioemotional outcomes are threefold. First, following previous studies, the younger cohort of 9-year olds would spend more time on digital technologies, especially on newer digital media and entertainment activities, and less time on TV, compared to the older cohort (Fomby et al. 2019; Goode et al. 2019). Second, younger cohorts (i.e. 2008 cohort) have a greater chance of using potentially harmful mobile digital technologies with higher frequency, which may increase socioemotional problems associated with digital use compared to older cohorts (i.e. 1998 cohort). Despite parents' efforts to supervise their children's digital time (Brito et al. 2018), young children today are more able to use smartphones and tablets to engage in digital activity at all hours of the day, potentially leading the young 2008 cohort to engage more frequently and deeply in risky digital behavior, with negative effects on their socio-emotional well-being compared to the older 1998 cohort. Third, considering the rising SES inequalities during a decade of strong austerity and recession in Ireland (Cantillon et al. 2017), SES inequalities in the impact of child digital engagement on socioemotional well-being might be larger for the younger generation of 9-year olds (born in 2008, a recession period) than for the older generation of 9-year olds (born in 1998, a booming economy period). By contrast, as changes in children's gender roles and attitudes tend to take several decades to emerge (Shu and Meagher 2018), we expect stability in gendered patterns of how children's technology use impacts their socioemotional well-being.

Hypothesis 3a: The younger 2008 cohort spends more time on digital technologies, especially in digital media and entertainment activities, and less on TV, compared to the older 1998 cohort. 
Hypothesis 3b: The hypothesized effects of digital technology use on higher socioemotional problems are stronger for the younger 2008 cohort than for the older 1998 cohort.

Hypothesis 3c: The effect of child digital use on socioemotional problems is moderated by SES to a higher extent for the youngest 2008 cohort than for the older 1998 cohort, but gender differences in how digital use impacts child socioemotional problems remain stable across cohorts.

\section{Data and Methods}

\subsection{Sample}

We use two comparable cohorts of the Growing Up in Ireland (GUI) study, a nationally representative multi-cohort longitudinal study of children living in Ireland (Williams et al. 2009). We use Wave 1 of the ' 1998 Child Cohort', which consists of a representative sample of 8568 children aged 9 who were born between 1st November 1997 and 31st October 1998. This group of children was first interviewed between August 2007 and May 2008. We also utilize Wave 5 of the '2008 Infant Cohort', which contains 8032 children aged 9 who were born between December 2007 and June 2008. Data collection for this Wave 5 was conducted between June 2017 and February 2018. While the current GUI only allows us to compare these two cohorts at 9 years old, the existing measures for these two cohorts provide an ideal comparative framework. Both cohorts gathered both parent completed and child completed indicators. Parents assessed their child's socioemotional problems, as measured by the SDQ, and average daily TV and digital screen-time, while children reported what digital activities they engaged in, their mobile phone ownership, and supervision on digital devices by adults. While questions for digital use changed between cohorts, the Wave 5 child questionnaire of the 2008 cohort was adapted so as to establish solid comparisons with Wave 1 of the 1998 cohort (i.e., by making the child questionnaire shorter) (see Quail et al. 2019).

Table 1 describes the cases missing from the two cohorts on the main variables of analysis. Overall, among the 16,600 observations within the two cohorts, approximately $20 \%$ of cases had missing responses on at least one of the variables of interest. Missing data affected the 1998 cohort slightly more (22.64\%) than the 2008 cohort $(18.14 \%)$. The majority of these differential missing cases came from the binary activity variables (Gaming, Media, Socializing, Education, Other) and the adult supervision indicator. Missingness along the child-reported variables was significantly lower in the 2008 cohort ( 10\%), than in the 1998 cohort $(\sim 18 \%)$. The missingness across the variables might be due to the fact that child-reported measures are often subject to increased missingness, due to factors like comprehension or boredom (Livingstone et al. 2018).

We conducted a number of robustness checks to examine missingness across the two cohorts. Little's MCAR tests (not shown) indicated that all six child-reported measures are completely missing at random and the missingness is independent of both the observed and unobserved data; this poses no significant bias to the analytic sample (Li 2013). Also, while missingness in SES is slightly higher for the youngest 
Table 1 Sample selection by cohort

\begin{tabular}{|c|c|c|c|c|c|c|}
\hline \multirow[t]{2}{*}{ Variables } & \multicolumn{2}{|c|}{$\begin{array}{l}\text { Overall Sample } \\
(n=16,600)\end{array}$} & \multicolumn{2}{|c|}{$\begin{array}{l}1998 \text { Child Cohort } \\
(n=8568)\end{array}$} & \multicolumn{2}{|c|}{$\begin{array}{l}2008 \text { Infant Cohort } \\
(n=8032)\end{array}$} \\
\hline & $\mathrm{n}$ Missing & $\%$ Missing & n Missing & $\%$ Missing & $\mathrm{n}$ Missing & $\%$ Missing \\
\hline Child Gender & 6 & 0.04 & 0 & 0.00 & 6 & 0.07 \\
\hline Parent Age & 6 & 0.04 & 0 & 0.00 & 6 & 0.07 \\
\hline Parental Employment Status & 0 & 0.00 & 0 & 0.00 & 0 & 0.00 \\
\hline Parental Education & 34 & 0.02 & 0 & 0.00 & 34 & 0.42 \\
\hline Household Social Class & 1010 & $0.20 *$ & 458 & 5.35 & 552 & 6.87 \\
\hline Region & 55 & 6.08 & 19 & 0.22 & 36 & 0.45 \\
\hline Single Parent & 6 & 0.33 & 0 & 0.00 & 6 & 0.07 \\
\hline TV Screen-time & 6 & 0.04 & 0 & 0.00 & 6 & 0.07 \\
\hline Digital Screen-time & 15 & 0.09 & 4 & 0.05 & 11 & 0.14 \\
\hline Games & 2428 & $14.63 *$ & 1605 & 18.73 & 823 & 10.25 \\
\hline Media & 2438 & $14.69^{*}$ & 1607 & 18.76 & 831 & 10.35 \\
\hline Socializing & 2439 & $14.69 *$ & 1610 & 18.79 & 829 & 10.32 \\
\hline Education & 2430 & $14.64 *$ & 1610 & 18.79 & 820 & 10.21 \\
\hline Personal Development & 2435 & $14.67 *$ & 1608 & 18.77 & 827 & 10.30 \\
\hline Mobile Phone Ownership & 174 & 1.05 & 52 & 0.61 & 122 & 1.52 \\
\hline Adult Supervision & 2535 & $15.27 *$ & 1613 & 18.83 & 922 & 11.48 \\
\hline Overall Sample & 16,600 & 100 & 8.568 & 100 & 8032 & 100 \\
\hline Missing Cases & 3397 & 20.46 & 1940 & 22.64 & 1457 & 18.14 \\
\hline Analytic Sample & 13,203 & 49.54 & 6628 & 77.36 & 6575 & 81.86 \\
\hline
\end{tabular}

Sample selection for the analytic sample construction, indicating when the missingness across variables between the 1998 and 2008 cohort is statistically significant at the level of $p<0.05\left(^{*}\right)$

cohort, additional analyses (not shown) reveal similar probabilities of missing data across all SES groups between the two cohorts. We decided to exclude all cases with missing values on at least one of the variables of interest $(n=3397,20.46 \%)$ for a final analytic sample of $n=13,397$ (79.54\% of the original sample).

\subsection{Dependent Variables}

Our main analyses used a continuous dependent variable to measure socioemotional well-being outcomes: the Strengths and Difficulties Questionnaire Total Difficulties Score (TDS). SDQ Total Difficulties Score (TDS) is regarded as 'a concise and wellvalidated tool' used to measure socioemotional well-being of 3 to 16-year-olds (Goodman and Goodman 2011). Throughout the literature discussed previously, well-being is largely defined as 'an abstract and wholly individualized concept whose meaning appears to be in constant flux' (Best et al. 2014). For our analyses, we utilize an objective conception of well-being that specifies positive well-being as healthy, congruent and vital functioning, rather than mere subjective experiences and perceptions of happiness (Castellacci and Tveito 2018). In utilizing the SDQ, we 
operationalize socioemotional problems to mean the prescience of emotional, conduct, hyperactivity, and peer relationship difficulties and socioemotional well-being as the absence of these problems.

The parent is asked to assess the applicability of 25 statements to their child's behavior with three response options: 'Not true', 'Somewhat true' or 'Certainly true'. These 25 responses generate scores on five subscales: (1) emotional symptoms; (2) conduct problems; (3) hyperactivity; (4) peer relationship problems; and (5) prosocial behavior. Subscales 1 through 4 are combined to generate a Total Difficulties Score (TDS) and assess overall psychosocial functioning and adjustment, with a minimum score of 0 (indicating the lowest socioemotional problems) and a maximum score of 40 (indicating the highest socioemotional problems). In additional analyses we subdivide the categories of TDS, and further add the SDQ Prosocial Score. This measure comes from the Prosocial subscale and calculates children's pro-social behavior on a scale from 0 to 10 . For the sake of comparability, we inverted the sign of the prosocial measure and named it 'anti-social behavior' (see Table 5).

\subsection{Independent Variables}

We used two measures for the quantity of screen-time: (i) time spent watching TV per average weekday and (ii) time spent on digital devices per average weekday (i.e., mobile phone, computer, tablet, and e-reader). These variables were measured by four categories: 'none', 'less than an hour', '1 to 3 hours', and '3 hours or more'. Although this will assess only digital technology time use on weekdays, 'measurements of weekday and weekend digital technology use have been shown to be highly correlated' (Orben et al. 2019).

We further employed five measures of the quality of digital engagement, used as binary dummy variables. These five categories separate children between those who engage in these activities on an average day (1=yes) and those wo do not $(0=$ no): (1) 'gaming'; (2) leisure (i.e. media); (3) information (i.e. education); (4) digital social interaction; (5) digital personal development. Table 6 provides details on the exact examples of activities that were included in each of these digital activities. The GUI child questionnaire designed questions in which children were given a list of digital activities and were asked which activities they currently did or did not engage in. Some activities included in the questionnaire changed and expanded from the 1998 to the 2008 cohort, responding to changes in the use of technologies during this decade difference. To address this inconsistency, digital activities were reclassified into a modified version of Van Deursen and Van Dijk's (2014) measure of 'Internet activity types' by excluding the 'commercial transaction' and 'news' activity types for use with child data.

Finally, we included two additional binary variables capturing digital access and technology family contexts: (1) 'mobile phone ownership' split the sample between children who own a smartphone $(1=$ yes $)$ and those who do not own a smartphone $(0=$ no); (2) 'adult supervision' was a variable differentiating between children with an adult that frequently or always supervises children's digital activities (1=yes) and otherwise $(0=$ no $)$. 


\subsection{Moderating and Control Variables}

Several sociodemographic, household, and parental characteristics were selected as covariates for the models, guided by previous research (Parkes et al. 2013; Hope et al. 2014; Orben and Przybylski 2019a). These measures came primarily from the GUI Primary Caregiver (PCG) Questionnaire, with the PCG being the caregiver within the household that provided the most care to the Study Child and knew most about him/ her. In $98 \%$ of cases, the Primary Caregiver was the child's mother.

We used two moderators and several controls. SES was coded into four categories: 'low-skilled routine', 'skilled routine', 'non-routine intermediate' and 'professional or managerial' (reference). 'All others gainfully occupied and unknown' were counted as missing $(N=1002)$, as these are cases where 'no precise allocation is possible' (CSO 2015; 105). This measure of SES utilized in the GUI is similar to the commonly used Erikson-Goldthorpe-Portocarero (EGP) occupational class schema. Socioeconomic status (SES) was generated from both the PCG and the Secondary Caregiver Questionnaires, with overall household SES taken as the highest SES of both partners in the household (as relevant). Due to sample size reasons, in some analyses we separated our sample by parental SES using a binary measure, differentiating between (i) professional and managerial class and (ii) otherwise. Gender was as a dummy variable of the gender attributed to the child: boy (0) or girl (1).

We included the following control variables: parental age (PCG, continuous); parental employment (PCG, binary); single parenthood (binary); Urban versus Rural locality (binary). On top of using SES, we included parental education as a control variable, as family SES and parental education play different roles in children's screen-based activities with well-being implications (Gracia 2015). Parental education had three categories on the highest level of education of the PCG: 'low secondary or lower', 'high secondary or vocational', and 'college education' (reference).

\subsection{Empirical Strategy}

Our analyses followed various steps. First, OLS linear regression models were conducted, which allowed comparison of coefficients to assess the magnitude and significance of the various independent and control variables on SDQ scores. Second, we examined the digital effects on well-being outcomes separately by gender and SES. Third, we run additional robustness checks with quantile regression models to examine how the impact of digital use varies across different SDQ scores. Quantile regressions are an extension of classical least squares estimation of conditional mean functions (in OLS regressions) to the estimation of conditional quantile functions. Quantile regressions allow for the estimation of heterogeneous effects of covariates at different levels of a dependent variable, without the inherent subsample selection biases of split sample analyses (Koenker and Hallock 2001). Fourth, we run additional analyses for sub-scales included in the SDQ scores, including anti-social behavior, to examine how child digital engagement effects differ across specific well-being measures. 


\section{Results}

\subsection{Descriptive Analyses}

Table 2 shows the descriptive statistics with means and standard deviations for all our variables of study, both overall and across the two cohorts. Parents in the 2008 cohort were older than in the 1998 cohort, with an increase of $8 \%$ in parents aged 40-49. Additionally, parents in the 2008 sample showed higher employment rates, in part reflecting the timing of the 1998 cohort's Age 9 wave during the 2007/08 economic recession. Parents in the 2008 cohort, compared to the 1998 cohort, had very few respondents with Lower Secondary education and more respondents with higher education, while the proportion of children with parents in professional and managerial classes was higher in the 2008 cohort than in the 1998 cohort.

Table 2 also shows relevant differences in the quantity of digital technology engagement. We observe that TV screen-time was slightly lower and digital screentime higher in the 2008 cohort, compared to the 1998 cohort. For example, in the 1998 cohort sample $73 \%$ of children spent over an hour watching TV, while this number dropped to $48 \%$ in the 2008 cohort sample; digital screen-time over an hour rose from $13 \%$ to $28 \%$ between the 1998 and the 2008 cohorts, with the proportion of non-users dropping by $9 \%$. These findings indicate that children are moving away from traditional TV screen-time and supplanting it with time spent on digital technologies (e.g. mobile phones, iPads, Tablets). This figure is line with the increase in mobile phone ownership at age 9 from $61 \%$ in the 1998 cohort to $78 \%$ in the 2008 cohort.

In Table 2 we further observe differences in the quality of digital engagement of 9year-olds across cohorts. We see small increases in both social and personal development digital engagement. There was also a marked decrease in child-reported educational use of digital technologies from $56 \%$ in the 1998 cohort to only $17 \%$ in the 2008 cohort. By contrast, children reporting engaging in media activities (e.g. watching YouTube, downloading or streaming movies/music/apps) jumped from only $28 \%$ in 1998 to $89 \%$ in 2008. This significant increase in digital media use may be explained by the proliferation of music and video streaming platforms (e.g. Netflix, YouTube, Spotify) over the last decade.

\subsection{Digital Use Effects on Child Socioemotional Wellbeing}

Table 3 presents the multivariate OLS models for SDQ Total Difficulties Scores (TDS). Analyses are presented for (i) the overall sample, adding both the 1998 and 2008 cohort (Column 1), (ii) the 1998 cohort only (Column 2) and (iii) the 2008 cohort only (Column 3). In this section we only discuss the results for the overall sample (Column 1).

In Table 3 (see Column 1), positive associations of the covariates with the dependent variable indicate an increase in socioemotional problems, and negative values a decline in socioemotional problems. Results are in line with $H$ - $1 a$ regarding screen-time. In the overall sample, TV Screen-time was only significantly associated with an increase in children's socioemotional problems at $3+$ hours of daily engagement $(B=1.527$; $p<0.001$, when compared to children who did not watch any TV. Digital screentime presents significant negative associations at 1 to $3 \mathrm{~h}(B=0.472 ; p<0.001)$ as well 
Table 2 Summary statistics of study variables

\begin{tabular}{|c|c|c|c|c|c|c|}
\hline \multirow[b]{2}{*}{ Variables } & \multicolumn{2}{|c|}{ Overall Sample } & \multicolumn{2}{|c|}{1998 Child Cohort } & \multicolumn{2}{|c|}{2008 Infant Cohort } \\
\hline & Mean & $\mathrm{SD}$ & Mean & $\mathrm{SD}$ & Mean & $\mathrm{SD}$ \\
\hline SDQ Total Difficulties Score & 6.998 & 4.986 & 7.024 & 4.788 & 6.972 & 5.178 \\
\hline SDQ Emotional Subscale & 1.907 & 1.938 & 1.914 & 1.916 & 1.902 & 1.961 \\
\hline SDQ Conduct Subscale & 1.127 & 1.331 & 1.180 & 1.360 & 1.075 & 1.301 \\
\hline SDQ Hyperactivity Subscale & 2.931 & 2.447 & 2.858 & 2.365 & 3.005 & 2.525 \\
\hline SDQ Peer Subscale & 1.031 & 1.390 & 1.072 & 1.369 & 0.990 & 1.411 \\
\hline SDQ Prosocial Subscale & 8.928 & 1.429 & 8.886 & 1.420 & 8.971 & 1.438 \\
\hline \multicolumn{7}{|l|}{ TV Screen-time } \\
\hline None & 0.04 & & 0.03 & & 0.06 & \\
\hline Less than an hour & 0.35 & & 0.24 & & 0.45 & \\
\hline 1 to $3 \mathrm{~h}$ & 0.55 & & 0.65 & & 0.46 & \\
\hline $3+$ hours & 0.06 & & 0.08 & & 0.03 & \\
\hline \multicolumn{7}{|l|}{ Digital Screen-time } \\
\hline None & 0.23 & & 0.22 & & 0.23 & \\
\hline Less than an hour & 0.56 & & 0.63 & & 0.49 & \\
\hline 1 to $3 \mathrm{~h}$ & 0.20 & & 0.14 & & 0.26 & \\
\hline $3+$ hours & 0.01 & & 0.01 & & 0.02 & \\
\hline \multicolumn{7}{|l|}{ Activities } \\
\hline Games & 0.85 & & 0.86 & & 0.84 & \\
\hline Media & 0.58 & & 0.28 & & 0.88 & \\
\hline Socializing & 0.25 & & 0.22 & & 0.29 & \\
\hline Education & 0.37 & & 0.56 & & 0.17 & \\
\hline Personal development & 0.52 & & 0.48 & & 0.56 & \\
\hline Mobile phone owner & 0.70 & & 0.61 & & 0.78 & \\
\hline Adult supervision & 0.60 & & 0.67 & & 0.54 & \\
\hline \multicolumn{7}{|l|}{ Child Gender } \\
\hline Boy & 0.49 & & 0.48 & & 0.51 & \\
\hline Girl & 0.51 & & 0.52 & & 0.49 & \\
\hline \multicolumn{7}{|l|}{ Parent Age } \\
\hline $20-39$ & 0.38 & & 0.41 & & 0.34 & \\
\hline $40-49$ & 0.59 & & 0.56 & & 0.62 & \\
\hline 50 or older & 0.03 & & 0.03 & & 0.04 & \\
\hline \multicolumn{7}{|l|}{ Parental employment status } \\
\hline Employed & 0.67 & & 0.62 & & 0.73 & \\
\hline Not in employment & 0.33 & & 0.38 & & 0.27 & \\
\hline \multicolumn{7}{|l|}{ Parental education } \\
\hline Lower secondary or less & 0.10 & & 0.14 & & 0.05 & \\
\hline Upper secondary/non-degree & 0.56 & & 0.57 & & 0.56 & \\
\hline College education & 0.34 & & 0.29 & & 0.39 & \\
\hline \multicolumn{7}{|l|}{ SES level } \\
\hline Professional and managerial class & 0.59 & & 0.58 & & 0.61 & \\
\hline
\end{tabular}


Table 2 (continued)

\begin{tabular}{|c|c|c|c|c|c|c|}
\hline \multirow[b]{2}{*}{ Variables } & \multicolumn{2}{|c|}{ Overall Sample } & \multicolumn{2}{|c|}{1998 Child Cohort } & \multicolumn{2}{|c|}{2008 Infant Cohort } \\
\hline & Mean & $\mathrm{SD}$ & Mean & $\mathrm{SD}$ & Mean & $\mathrm{SD}$ \\
\hline Non-routine intermediate class & 0.19 & & 0.20 & & 0.17 & \\
\hline Skilled routine class & 0.13 & & 0.14 & & 0.12 & \\
\hline Low-skilled routine class & 0.09 & & 0.08 & & 0.10 & \\
\hline \multicolumn{7}{|l|}{ Region } \\
\hline Urban & 0.43 & & 0.46 & & 0.41 & \\
\hline Rural & 0.57 & & 0.54 & & 0.59 & \\
\hline Single Parents & 0.07 & & 0.07 & & 0.08 & \\
\hline$N$ & 13,203 & & 6628 & & 6575 & \\
\hline
\end{tabular}

Means and Standard Deviations

Source: Growing Up in Ireland (GUI) Survey

as $3+$ hours $(B=1.708 ; p<0.001)$, indicating an increasing magnitude and stronger effects of digital screen-time on child socioemotional problems as screen-time increased.

Additionally, Column 1 of Table 3 shows that media use was the only digital activity with a significant (positive) association with socioemotional problems among 9-yearold children, $(B=1.527 ; p<0.001)$. The coefficients for all the other digital activities, including Gaming, Socializing, Education, and Personal Development, were found to be non-significant. These results are partially in line with our $H-1 b$. While media/ entertainment digital activities were associated with an increase in socioemotional problems, the positive effects of digital socializing and gaming on socioemotional problems, and negative effects of involvement in digital educational activities, were small and not statistically significant.

Finally, Column 1 in Table 3 presents some other relevant findings. Interestingly, mobile phone ownership was associated with less socioemotional problems $(B=$ $-0.231 ; p<0.05)$ and adult digital supervision with more socioemotional problems $(B=0.211 ; p<0.05)$. This might suggest that (i) not owing a mobile phone limits some positive elements for children's social capital and connectedness (Verduyn et al. 2017) and (ii) that parents active digital supervision is partly a response of children's intrinsic socioemotional problems (Valkenburg and Piotrowski 2017). As for gender, consistent with previous literature (Ortega et al. 2010; Booker et al. 2018), boys had higher risks of showing socioemotional problems than girls $(B=-0.859 ; p<0.001)$. Regarding parental education, children of parents with low secondary or lower education $(B=$ $1.549 ; p<0.001)$ and with higher secondary or vocational education $(B=0.557$; $p<0.001$ ), reported lower socioemotional problems than children with parents having higher education. As for parental SES, children of both low-skilled routine workers $(B=0.359 ; p<0.05)$ and skilled routine workers $(B=0.519 ; p<0.001)$ had higher levels of socioemotional problems, compared to children with parents having professional and managerial occupations. These findings are consistent with previous literature indicating that socioeconomic inequalities have negative impacts on 
Table 3 Linear regression models on child's socioemotional problems (SDQ)

\begin{tabular}{|c|c|c|c|c|c|c|}
\hline \multirow[b]{2}{*}{ Variables } & \multicolumn{2}{|l|}{ Overall sample } & \multicolumn{2}{|l|}{1998 Cohort } & \multicolumn{2}{|l|}{2008 Cohort } \\
\hline & $b$ & SE & $b$ & SE & $b$ & SE \\
\hline \multicolumn{7}{|l|}{ TV screen-time } \\
\hline \multicolumn{7}{|l|}{ None (Ref) } \\
\hline Less than an hour & -0.279 & $(0.219)$ & -0.628 & $(0.370)$ & -0.119 & $(0.277)$ \\
\hline 1 to $3 \mathrm{~h}$ & 0.254 & $(0.216)$ & -0.123 & $(0.360)$ & 0.464 & $(0.277)$ \\
\hline $3+$ hours & $1.527^{* * * *}$ & $(0.278)$ & $1.042^{*}$ & $(0.410)$ & $2.080^{* * *}$ & $(0.460)$ \\
\hline \multicolumn{7}{|l|}{ Digital screen-time } \\
\hline \multicolumn{7}{|l|}{ None (Ref) } \\
\hline Less than an hour & 0.063 & $(0.106)$ & -0.002 & $(0.143)$ & 0.141 & $(0.158)$ \\
\hline 1 to $3 \mathrm{~h}$ & $0.472^{* * *}$ & $(0.134)$ & $0.536^{* *}$ & $(0.203)$ & $0.393^{*}$ & $(0.185)$ \\
\hline $3+$ hours & $1.708^{* * *}$ & $(0.371)$ & 0.820 & $(0.650)$ & $1.944^{* * *}$ & $(0.471)$ \\
\hline Gaming & 0.079 & $(0.119)$ & -0.162 & $(0.168)$ & 0.217 & $(0.177)$ \\
\hline Media & $0.460^{* * * *}$ & $(0.092)$ & $0.408^{* *}$ & $(0.130)$ & $0.498^{*}$ & $(0.204)$ \\
\hline Social & 0.144 & $(0.102)$ & 0.141 & $(0.146)$ & 0.188 & $(0.144)$ \\
\hline Education & -0.123 & $(0.092)$ & -0.111 & $(0.119)$ & -0.087 & $(0.167)$ \\
\hline Personal development & -0.023 & $(0.088)$ & 0.083 & $(0.122)$ & -0.085 & $(0.130)$ \\
\hline Mobile phone owner & $-0.231^{*}$ & $(0.097)$ & -0.234 & $(0.123)$ & -0.166 & $(0.157)$ \\
\hline Adult supervision & $0.211^{*}$ & $(0.090)$ & $0.336^{* *}$ & $(0.128)$ & 0.090 & $(0.127)$ \\
\hline Girl & $-0.859^{* * *}$ & $(0.085)$ & $-0.547^{* * *}$ & $(0.116)$ & $-1.169^{* * *}$ & $(0.126)$ \\
\hline Parent age & $-0.809^{* * *}$ & $(0.080)$ & $-0.930^{* * *}$ & $(0.109)$ & $-0.689^{* * *}$ & $(0.118)$ \\
\hline Parent employed & -0.156 & $(0.098)$ & 0.023 & $(0.128)$ & $-0.371^{*}$ & $(0.152)$ \\
\hline Single parent & $1.399^{* * *}$ & $(0.167)$ & $1.531^{* * *}$ & $(0.240)$ & $1.279^{* * *}$ & $(0.234)$ \\
\hline \multicolumn{7}{|l|}{ Parent education } \\
\hline \multicolumn{7}{|l|}{ College education (Ref) } \\
\hline Low secondary or lower & $1.549^{* * * *}$ & $(0.152)$ & $1.591^{* * * *}$ & $(0.175)$ & $1.745^{* * * *}$ & $(0.302)$ \\
\hline High secondary or vocational & $0.557^{* * * *}$ & $(0.170)$ & $0.711^{* * * *}$ & $(0.206)$ & $0.420^{* * *}$ & $(0.319)$ \\
\hline \multicolumn{7}{|l|}{ SES level } \\
\hline \multicolumn{7}{|l|}{ Professional or managerial (Ref) } \\
\hline Non-routine intermediate class & 0.217 & $(0.118)$ & 0.187 & $(0.156)$ & 0.251 & $(0.178)$ \\
\hline Skilled routine & $0.519^{* * * *}$ & $(0.140)$ & $0.525^{* *}$ & $(0.186)$ & $0.533^{*}$ & $(0.212)$ \\
\hline Semi-/un-skilled routine & $0.359^{*}$ & $(0.163)$ & 0.195 & $(0.229)$ & $0.504^{*}$ & $(0.234)$ \\
\hline Rural & $-0.191^{*}$ & $(0.087)$ & 0.136 & $(0.118)$ & $-0.535^{* * *}$ & $(0.128)$ \\
\hline Constant & $9.781^{* * * *}$ & $(0.490)$ & $9.502^{* * * *}$ & $(0.698)$ & $10.49^{* * * *}$ & $(0.764)$ \\
\hline$N$ & 13,203 & & 6628 & & 6575 & \\
\hline adj. $R^{2}$ & 0.058 & & 0.061 & & 0.060 & \\
\hline
\end{tabular}

Standard errors in parentheses

Source: Growing Up in Ireland (GUI) Survey

${ }^{*} p<0.05,{ }^{* *} p<0.01,{ }^{* * *} p<0.001$

socioemotional well-being (Davis et al. 2010; Bøe et al. 2012, Klanšček et al. 2014; Piotrowska et al. 2015). 


\subsection{Cohort Digital Effects on Child Socioemotional Wellbeing}

Table 3 (see Column 2 and Column 3) shows that the effects of screen-time on socioemotional outcomes increased in the last decade. Spending 3+ hours of TV time was associated with an increase of socioemotional problems for both the 1998 and 2008 cohort. But this association was higher in size and stronger in statistical significance for the 2008 cohort $(B=2.080 ; p<0.001)$ than for the 1998 cohort $(B=1.042$; $p<0.05)$. As for digital engagement, the association between $3+$ hours of digital screen-time and socioemotional problems was again larger and stronger in terms of statistically significance for the 2008 cohort $(B=1.944 ; p<0.001)$ than for the 1998 cohort $(B=0.820)$. Spending '1 to 3 hours' of digital screen-time, compared to spending none in digital activities, was quite similarly associated with higher socioemotional problems in the cohort $1998(B=0.536 ; p<0.01)$ than in the 2008 cohort $(B=0.393 ; p<0.05)$.

Table 3 shows stability in the effects of the types of digital use on socioemotional problems between the 1998 cohort (Column 2) and the 2008 cohort (Column 3). The positive association between children's engagement in media activities and socioemotional problems was very similar for the 1998 cohort $(B=0.408 ; p<0.05)$ and the 2008 cohort $(B=0.498 ; p<0.01)$. The effects of the other digital activities of our study were small and statistically insignificant. Except for gaming, where the coefficient was negative for the 1998 cohort and positive for the 2008 cohort, the direction of associations between digital activity types and child socioemotional wellbeing went in the same direction. See Fig. 4 in the Appendix for a complementary graphical representation of the main cohort effects shown in Column 2 and Column 3 of Table 3.

Overall, the analyses of our cohort effects were partly in line with $H-3 b$. While the positive associations with socioemotional problems were stronger in the younger 2008 cohort than in the 1998 cohort (as expected), the types of digital activities in which 9years old participated had persistent effects on socioemotional problems across both cohorts where we expected stronger effects for the 2008 cohort than for the 1998 cohort.

\subsection{The Role of Gender and SES}

Figure 1 presents the main results of the multivariate linear regression models on SDQ Total Difficulties scores, separately by gender (left) and SES (right). Gender and SES played a minor role in moderating the impact of child digital engagement on socioemotional problems. We only found some exceptions in this regard. Educational digital activities were associated with a decline in socioemotional problems for boys $(p<0.05)$, having neutral effects for girls. By contrast, owning a mobile phone was associated with lower socioemotional problems among girls $(p<0.05)$, with neutral effects for boys. As for SES, gaming had neutral effects for high-SES children and was quite clearly associated with higher socioemotional problems for low-SES children $(p<0.05)$. In short, globally, gender and SES did not moderate the effect of child digital usage on socioemotional problems.

Figure 2 shows the multivariate linear regressions results on SDQ Total Difficulties scores, split by gender and cohort. Most of the minor gender differences observed in 

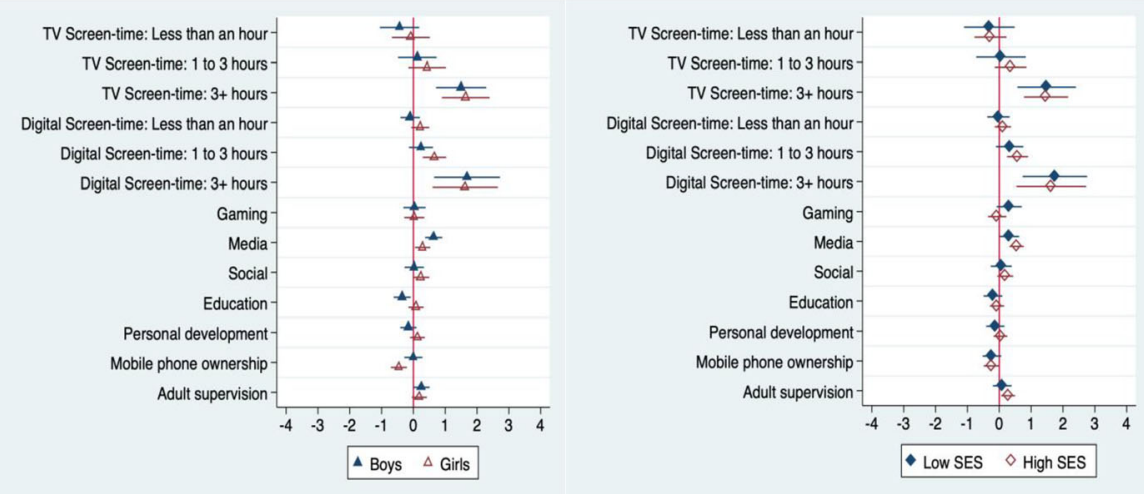

Fig. 1 Linear Regression Models. Child Socioemotional Problems (SDQ) by Gender and Socioeconomic Status (SES) in Overall Sample. Note: Regression coefficients for selected variables separately by gender and SES from the overall sample $(\mathrm{N}=13,203)$ with Confidence Intervals at the $95 \%$ level, adjusting for all the study control variables

Fig. 1 remained stable across cohorts. There were only some exceptions. For the 1998 cohort, spending $3+$ hours of digital screen-time led to high socioemotional problems among girls $(p<0.05)$, having neutral effects among boys. By contrast, for the 2008 cohort, $3+$ hours of digital screen-time led to high socioemotional problems for both girls and boys $(p<0.05)$. Personal development activities were associated with higher socioemotional problems among girls in the 1998 cohort $(p<0.05)$, with neutral effects on girls' socioemotional problems in the 2008 cohort. Overall, despite some exceptions, the effects of child digital engagement on socioemotional problems were quite similar between boys and girls across both cohorts.

Figure 3 shows the main multivariate linear regressions on SDQ Total Difficulties scores by SES and cohort. SES differences were small in both cohorts, with very few exceptions. Both low-SES and high-SES children increased their socioemotional problems associated with gaming over these ten years, low-SES children always more
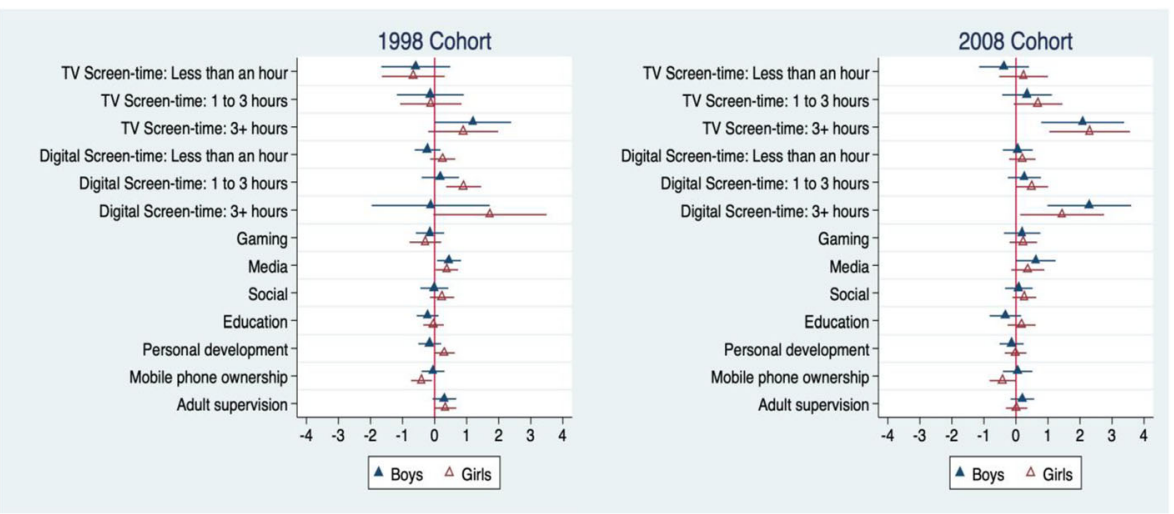

Fig. 2 Linear Regression Models. Child Socioemotional Problems (SDQ) by Gender and Cohort. Note: Regression coefficients for selected variables separately by gender, differentiating between the 1998 cohort $(\mathrm{N}=6628)$ and 2008 cohort $(\mathrm{N}=6575)$, with Confidence Intervals at the $95 \%$ level, adjusting for all the study control variables 
affected by gaming. Media usage was associated with higher socioemotional problems among high-SES children in both the 1998 and 2008 cohort $(p<0.05)$, while such association for low-SES children became neutral for the 2008 cohort. Despite some exceptions, the moderating role of SES in the impact of digital use on child socioemotional problems was small and insignificant across both cohorts.

Overall, the moderating role of gender and SES was minor and similar across cohorts. We found no general support for $H-2 a$ and $H-2 b$. Gender and SES tended to not moderate the association between child digital use and socioemotional problems. We found mixed support for $H-3 c$. Across cohorts, gender gaps were similarly low (as expected), as well as SES gaps (we expected higher SES gaps for the 2008 cohort than for the 1998 cohort).

\subsection{Robustness Checks: Quantile Regressions, SDQ Subscales and Heterogeneous Digital Use}

We conducted several robustness checks. First, we run quantile regression analyses of children's digital use on socioemotional problems (Table 4). 3+ hours of digital screentime was associated with higher socioemotional problems across nearly all TDS score levels. Yet, the size of the effects increased across the conditional distribution, with children with the lowest socioemotional problems being largely unaffected by their digital engagement, and children with highest socioemotional problems being disproportionately affected by digital engagement. For digital screen-time, 3+ hours daily screen-time was particularly salient in the 90th percentile (highest socioemotional problems) $(B=3.575 ; p<0.001)$, and smaller and insignificant at the 10 th percentile (lowest socioemotional problems) $(B=0.607)$. Likewise, 1 to $3 \mathrm{~h}$ of daily screen-time only reached significant associations with higher socioemotional problems in the 75th percentile $(B=0.568 ; p<0.05)$ and 90 th percentiles $(B=1.173 ; p<0.001)$. Similarly, engagement in digital media began to form an increasing association with socioemotional problems in the 25 th percentile $(B=0.282 ; p<0.01)$ up to the 90 th percentile $(B=0.705 ; \mathrm{p}<0.01)$, with a small and insignificant effect for the 10th
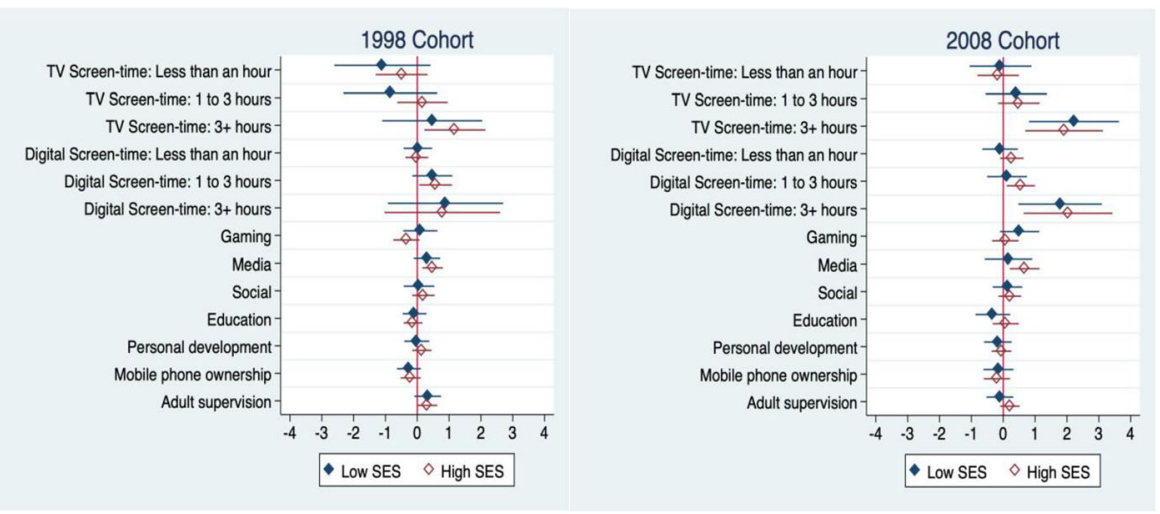

Fig. 3 Linear Regression Models. Child Socioemotional Problems (SDQ) by Socioeconomic Status (SES) and Cohort. Note: Regression coefficients for selected variables separately by SES, differentiating between the 1998 cohort $(N=6628)$ and 2008 cohort $(N=6575)$, with Confidence Intervals at the $95 \%$ level, and adjusting for all the study control variables 
percentile $(B=0.182)$. Additional quantile regression analyses (not shown) revealed that digital screen-time was more strongly associated with socioemotional problems across the conditional distribution in the 1998 cohort, while for the 2008 cohort there were more similar digital effects across SDQ levels.

Second, we conducted analyses on the effect of digital use on children's five specific socioemotional outcomes (Table 5). For digital screen time, 3+ hours of daily use had significant associations with higher socioemotional problems, except that less than an hour of TV screen-time (compared to not watching TV at all) was associated with declines in socioemotional problems for peer and for the anti-social subscales. Effects of digital time were generally stable over the five subscales. By contrast, media usage was associated with a substantive increase of socioemotional problems in two subscales (conduct, hyperactivity) but it was weakly associated with other three outcomes (emotional, peer and anti-social). Additional analyses (not shown) revealed a similar direction of the most relevant effects across cohorts, yet with slightly stronger effects for the 2008 cohort, compared to the 1998 cohort.

Third, we examined gender and SES differences in digital engagement (Table 7; Appendix). We found that boys were more active than girls in digital activities, especially for the 2008 cohort. Girls were more involved in socializing digital activities and were more digitally supervised by adults, while boys were more involved in digital personal development activities. We found that low-SES children spent more time watching TV and on digital activities than high-SES children, while SES gaps in digital screen-time clearly increased for the 2008 cohort. In both cohorts, high-SES children were overrepresented among those owning a mobile phone. For the 1998 cohort, high-SES children were less supervised by adults and engaged more with socializing and educational activities, while such patterns reversed for the 2008 cohort. These results show that, even if gender and SES were not found to moderate the effect of children's digital engagement on socioemotional problems, there were relevant gender and SES differences in children's digital engagement across the two cohorts, especially for the 2008 cohort.

\section{Discussion}

This study is - to our knowledge - the first cohort comparison of the impact of digital engagement on socioemotional outcomes. Using unique cohort data from Ireland on 9-year old children born a decade apart (in 1998 and 2008), we found both change and persistence in children's digital usage and its impact on well-being. While some hypotheses were generally confirmed ( $H-1, H-3 a, H-3 b)$, other hypotheses were rejected $(H-2 a, H-2 b)$, and some yielded mixed findings $(H-3 c)$. We globally discuss our mixed results in this section.

Four main findings can be highlighted. First, we found increased and slightly more diversified digital use in the birth cohort of 1998 than in the birth cohort of 2008. In line with findings of TV screen-time being functionally displaced by digital screen-time (Gershuny 2003; De Waal and Schoenbach 2010; Vilhelmson et al. 2018), TV screentime decreased between cohorts, while digital screen-time increased. This increase in digital screen-time is consistent with previous research, which has found moderate but consistent increases in digital screen-time between child cohorts since the 1990s (Vilhelmson et al. 2018; Goode et al. 2019; Fomby et al. 2019). Although there were modest increases to engagement in socializing and personal development activities, the 


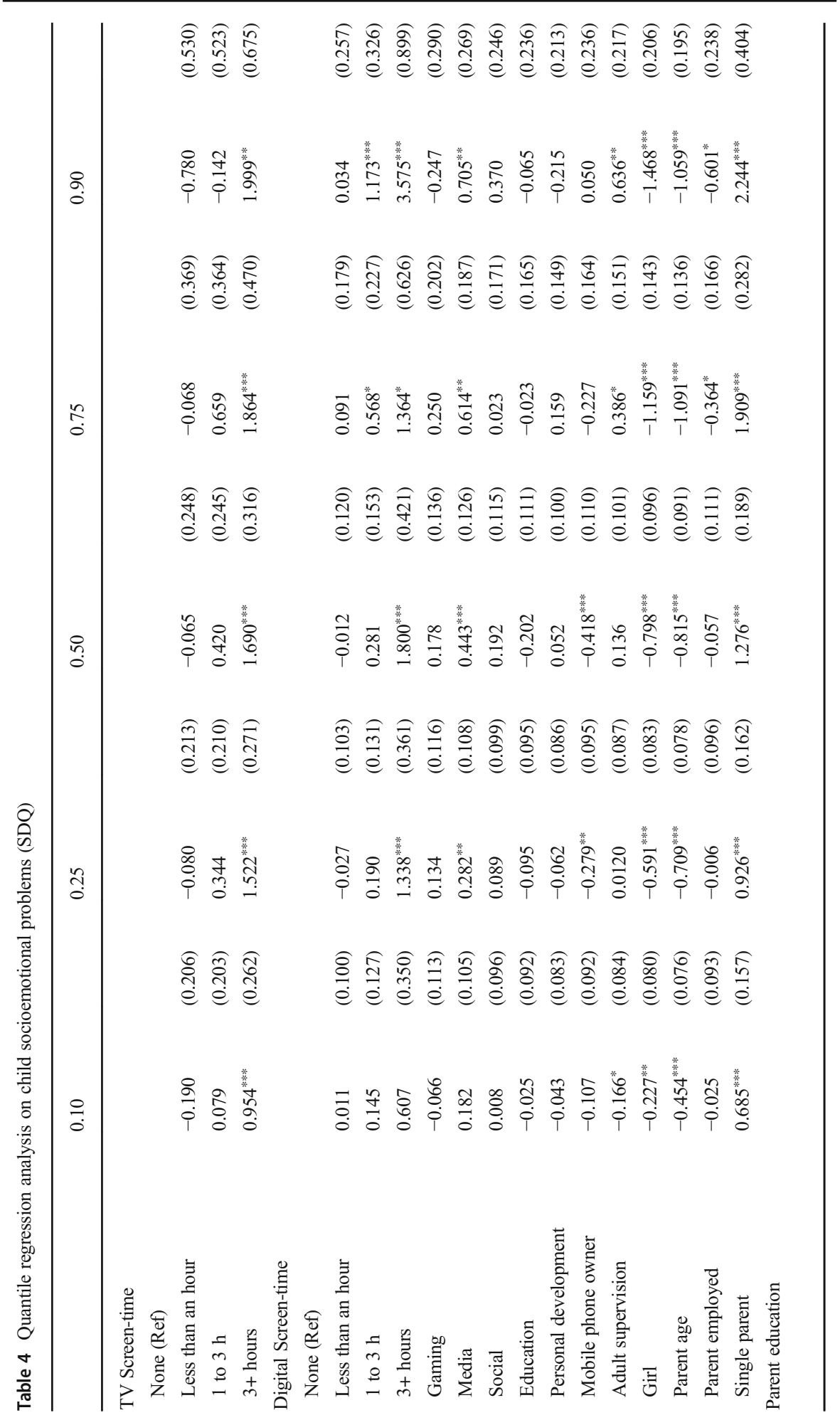




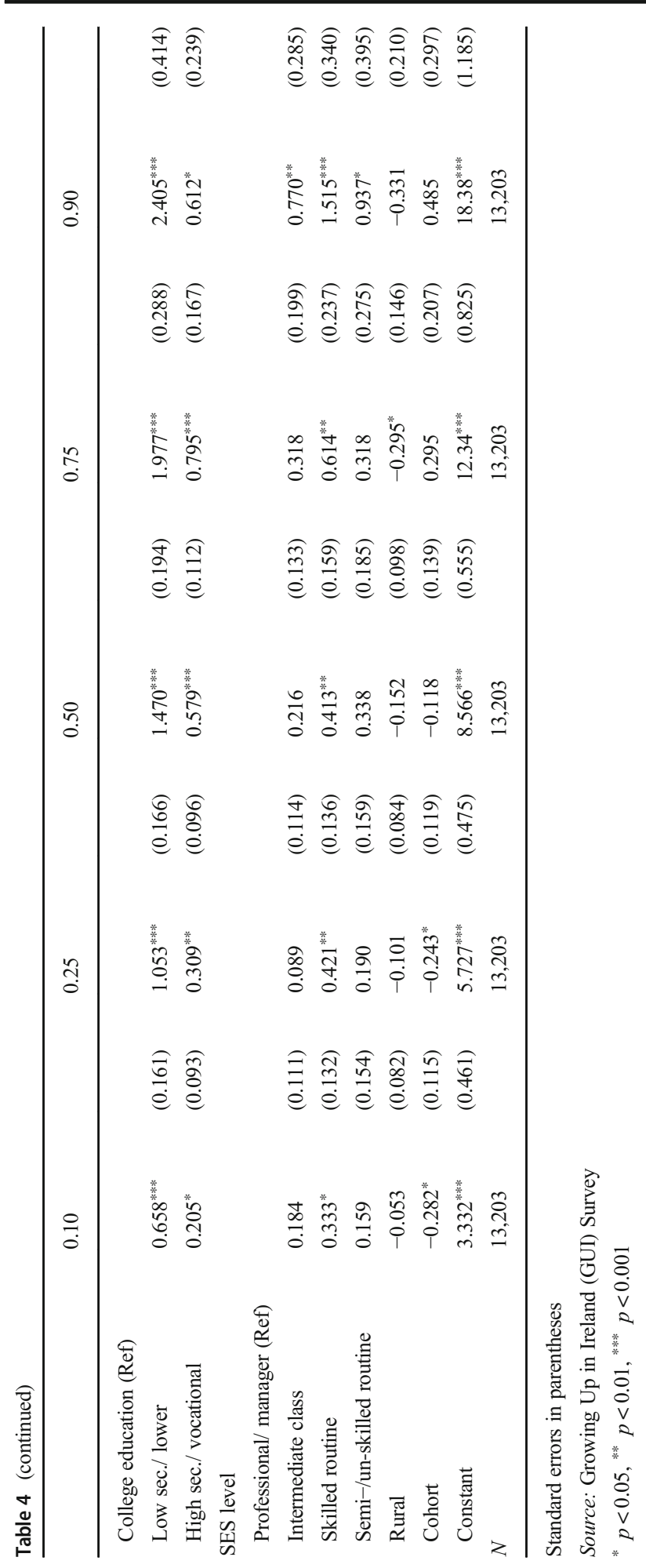




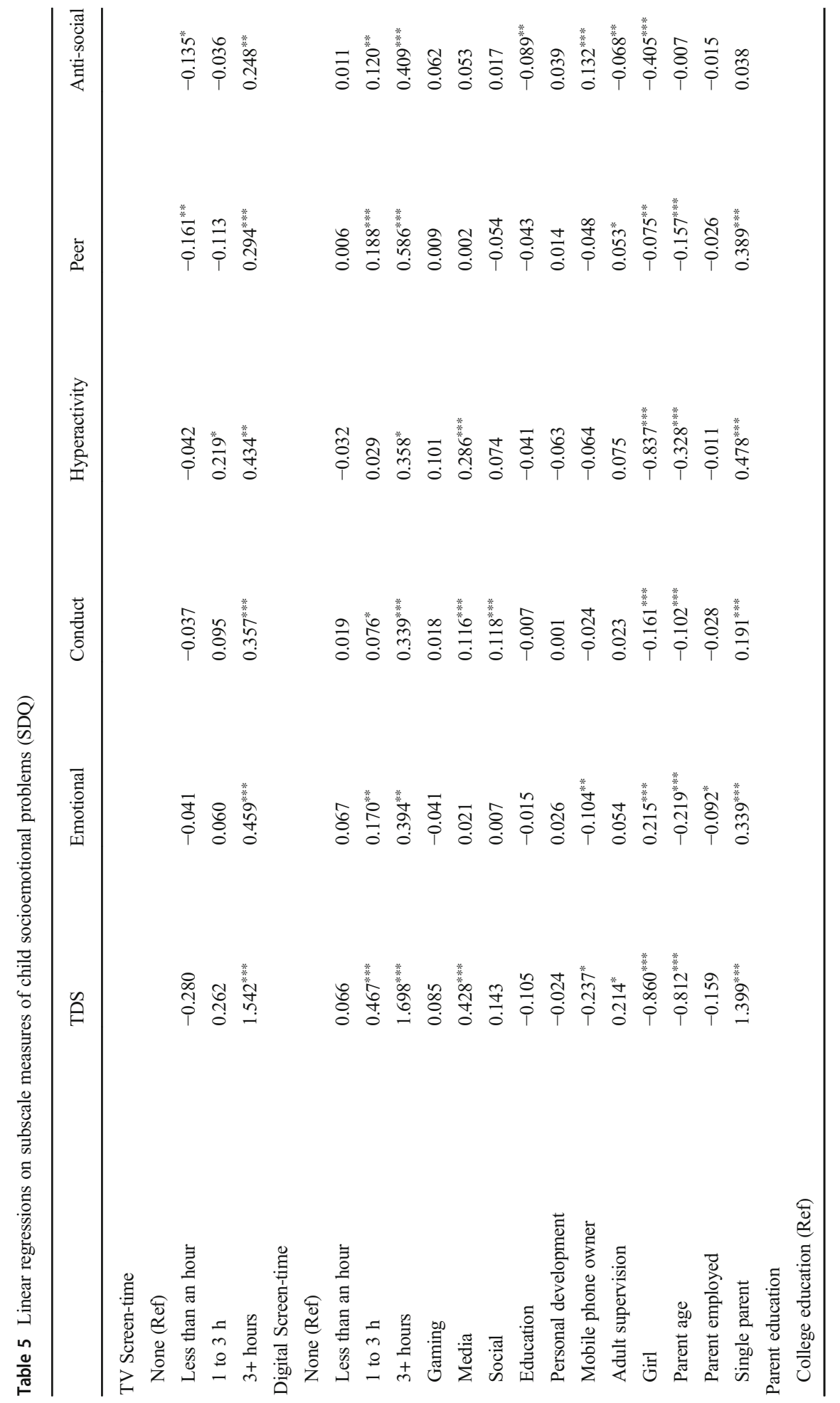




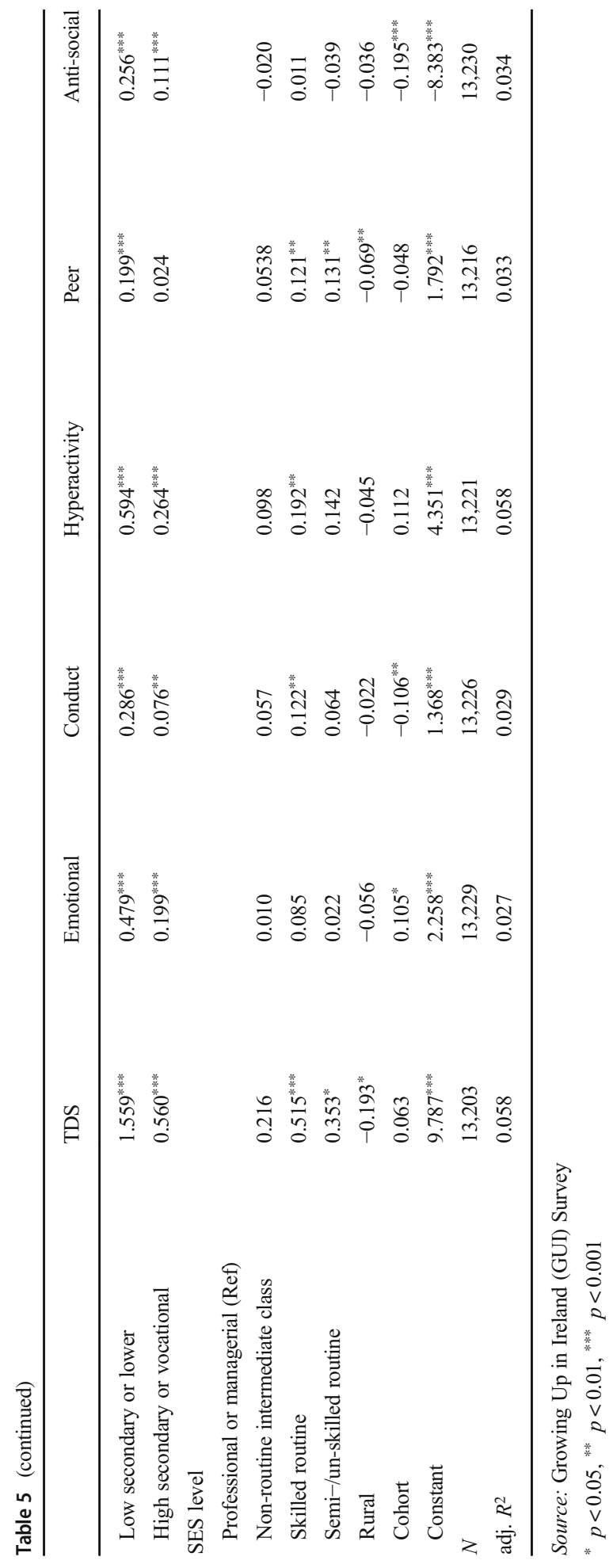


far greatest change in child digital activity usage comes with media/leisure activities (e.g. watching Youtube videos, listening to music, streaming TV/movies), which went from $28 \%$ of users in the 1998 cohort to $88 \%$ of users among the 2008 cohort. Indeed, with the ever-increasing capabilities of digital devices and emergence of video and streaming platforms (e.g. Youtube, Spotify, Netflix, etc.) 'digitod' children have new access to digital media and leisure activities that were unavailable to children born a decade earlier.

Second, we found high levels of daily TV/digital screen-time (i.e. 3+ hours) to be associated with significant declines in child socioemotional well-being. The size of such effects was about twice as large for the 2008 cohort, compared to the 1998 cohort. Most digital activities (i.e., gaming, educational, socializing) had small and insignificant effects on children's socioemotional well-being. Yet, we found engagement in digital media activities to lead to increasing child socioemotional problems, with similar effects for the 1998 and 2008 cohort. Our results generally support recent research showing significant negative effects of digital screen-time on child well-being (e.g., Twenge et al. 2018). These findings link to literature implying that examining both the quantity and quality of digital engagement is crucial for the child well-being literature (Livingstone et al. 2018), while indicating increasing negative effects of high screen-based time on child socioemotional well-being in contemporary Ireland.

Third, we found the effects of digital use on socioemotional well-being to be quite similar by gender and SES in both cohorts. This finding is relevant, especially considering that additional analyses showed gender and SES differences in child digital engagement, in line with previous scholarship (Brooks et al. 2016; Gracia et al. 2019; O'Neill and Dinh 2015; Ortega et al. 2010). These findings with regard to SES are particularly important due to the marked differences in the economic circumstances of the two cohorts. Girls were more active in socializing digital activities, while boys engaged more in personal development digital activities, with boys being overrepresented among mobile phone owners. Low-SES children, despite having lower rates of mobile phone ownership than high-SES children, spent more time on screen-based activities. Also, some of these gaps in digital activities were clearly stronger for the younger 2008 cohort, compared to the older 1998 cohort. And yet, despite significant cohort changes in digital use, parental characteristics (e.g. employment, education, age), and economic circumstances, we found similar effects of digital engagement on child socioemotional well-being by gender and SES and across cohorts. This might indicate that gender and SES inequalities in socioemotional well-being are not driven by distinct forms of digital engagement. Future research should further examine the role of gender and SES in influencing child digital engagement and well-being.

Fourth, in additional analyses we further identified at which levels of socioemotional well-being children are most affected by digital engagement. Digital screen-time and media engagement had the strongest detrimental effects on well-being among children who were already at high levels of risk (i.e. high socioemotional problems), but more modest effects among those at the lowest risk levels. Further, we found that child media engagement is associated with conduct and hyperactivity, but not with emotional, peer, and anti-social subscales. These findings support the claims of Valkenburg and Piotrowski (2017) in suggesting that the effects of child digital engagement on wellbeing differ across risks levels and depending on the well-being indicator that we examine. Further analyses (not shown) did not give conclusive evidence of cohort 
variations on how children's digital engagement impacts their socioemotional risks and specific psychological measures. We hope these analyses will inspire future studies looking at the (changing) effects of digital engagement on child well-being measures, beyond looking at average digital effects.

Our study has some shortcomings that we need to stress. First, our data, while spanning two cohorts, is cross-sectional in nature. Unfortunately, at this stage, there is only comparable data for 9-years old through the GUI, given that age 9 is the most recent currently available wave from the 2008 cohort. We hope that in the years to come our study will guide new cohort comparisons benefiting from high-quality longitudinal data. Second, our data had a relatively small number $(N=190)$ of participants who were 'high users' (3+ hours daily) of digital technology. This led to large confidence intervals in some analyses and meant that caution needs to be taken in drawing conclusions from this category. Still, our results use a large representative sample of Irish children, indicating that the observed effect sizes are generally reliable and accurate. Third, the TV and digital time use data and SDQ scores from the GUI are parent-reported, rather than child-reported, which adds challenges to the reliability of some the data (Noonan et al. 2018). While the GUI corrected for this in various ways (i.e., adjusting the time and difficulty of the child questionnaires), weneed to stress this limitation, calling for future comparisons. Fourth, while we used reliable and comparable digital time-use measures, scholars have recommended the use 24-hour time-diary measures as reliable indicators to assess children's activities and their related well-being outcomes (Ben-Arieh and Ofir 2002; Gracia 2020). Unfortunately, such time-diary data were not available in our data when we conducted our study. Future research will hopefully further address these caveats by using related high-quality data.

To conclude, our study - despite having some limitations - is the first examination of how child digital usage impacts socioemotional well-being and how these impacts have changed across recent cohorts. We find both change and persistence in how 9-years old children engage in digital technologies and how this digital involvement affects their socioemotional wellbeing. A decade of difference between two cohorts in Ireland (the 1998 cohort and the 2008 cohort) has led to significant changes in the nature of digital engagement. While the negative effects of the quantity of child screen-based time on socioemotional well-being have become more pervasive in the younger generation of children, the relative effect of the quality of this digital engagement (forms of digital and screen engagement) on child well-being has remained quite stable over the last decade in Ireland. We hope that our study will inspire new observational and experimental research on the changing nature of child digital engagement and its impacts on well-being.

Authors' Contributions Bohnert was the main leading author of this study. The idea was developed by Bohnert and Gracia. The analyses were conducted by Bohnert. The first draft was written by Bohnert and, subsequently, both Bohnert and Gracia contributed to the writing of the study.

Funding This study is integrated within the DIGYMATEX project (Grant agreement ID: 870578), funded by the European Commission H2020 within the call 'DT-TRANSFORMATIONS-07-2019 - The impact of technological transformations on children and youth.' Project link: http://www.digymatex.eu.

Data Availability The data used in this study were obtained from the Growing Up in Ireland (GUI) study, following all the ethical and formal criteria within the Irish Social Science Data Archive (ISSDA) and according to EU data protection policies. 


\section{Compliance with Ethical Standards}

Conflict of Interest This study has no conflict of interest of any sort.

Code Availability Analyses were conducted with the statistical software Stata 16. Data coding will be made accessible to the scientific community.

\section{Appendix}

Table 6 Digital activities definition

\begin{tabular}{|c|c|c|}
\hline Activity Types & 1998 Cohort & 2008 Cohort \\
\hline Gaming & Playing games & $\begin{array}{l}\text { Play games on your own } \\
\text { Play games with other people }\end{array}$ \\
\hline Media & $\begin{array}{l}\text { Watching movies and } \\
\text { downloading music }\end{array}$ & $\begin{array}{l}\text { Watch videos on YouTube } \\
\text { Watch TV or movies on the Internet } \\
\text { Downloading apps } \\
\text { Download or stream music or films }\end{array}$ \\
\hline Educational & $\begin{array}{l}\text { Doing homework } \\
\text { Surfing the internet for school projects }\end{array}$ & Doing homework \\
\hline Socializing & $\begin{array}{l}\text { Chatrooms } \\
\text { Instant messaging } \\
\text { E-mailing }\end{array}$ & $\begin{array}{l}\text { Visit a social media site } \\
\text { Instant messaging } \\
\text { Share photos, videos or music } \\
\quad \text { with people other than your family }\end{array}$ \\
\hline Personal Development & $\begin{array}{l}\text { Surfing the internet for things } \\
\text { that interest you }\end{array}$ & $\begin{array}{l}\text { Search for information on things } \\
\text { that interest you }\end{array}$ \\
\hline
\end{tabular}

Source: Growing Up in Ireland Survey (GUI) Survey. Child Questionnaires

Table 7 Children's digital engagement by gender and SES

\begin{tabular}{|c|c|c|c|c|c|c|c|c|}
\hline \multirow{3}{*}{ Variables } & \multicolumn{4}{|c|}{ GENDER } & \multicolumn{4}{|c|}{ PARENTAL SES } \\
\hline & \multicolumn{2}{|c|}{1998 Cohort } & \multicolumn{2}{|c|}{2008 Cohort } & \multicolumn{2}{|c|}{1998 Cohort } & \multicolumn{2}{|c|}{2008 Cohort } \\
\hline & Boys & Girls & Boys & Girls & Low & High & Low & High \\
\hline \multicolumn{9}{|l|}{ TV screen-time } \\
\hline None & 0.03 & 0.02 & 0.06 & 0.05 & 0.02 & $0.03 \mathrm{~b}$ & 0.05 & $0.06^{b}$ \\
\hline Less than an hour & 0.23 & 0.25 & 0.44 & 0.47 & 0.20 & $0.27^{b}$ & 0.42 & $0.48^{b}$ \\
\hline 1 to $3 \mathrm{~h}$ & 0.66 & 0.64 & 0.46 & 0.45 & 0.68 & $0.62 \mathrm{~b}$ & 0.49 & $0.44^{b}$ \\
\hline $3+$ hours & 0.08 & 0.08 & 0.03 & 0.03 & 0.10 & $0.07 \mathrm{~b}$ & 0.04 & $0.02 \mathrm{~b}$ \\
\hline \multicolumn{9}{|l|}{ Digital screen-time } \\
\hline None & 0.24 & $0.21^{\mathrm{a}}$ & 0.23 & $0.24^{\mathrm{a}}$ & 0.23 & 0.22 & 0.20 & $0.25^{b}$ \\
\hline Less than an hour & 0.61 & $0.64^{\mathrm{a}}$ & 0.45 & $0.52^{a}$ & 0.61 & 0.64 & 0.47 & $0.50^{b}$ \\
\hline 1 to $3 \mathrm{~h}$ & 0.14 & $0.14^{\mathrm{a}}$ & 0.29 & $0.14^{\mathrm{a}}$ & 0.22 & 0.13 & 0.30 & $0.23^{b}$ \\
\hline $3+$ hours & 0.01 & $0.01^{\mathrm{a}}$ & 0.01 & $0.02^{\mathrm{a}}$ & 0.02 & 0.01 & 0.03 & $0.01 \mathrm{~b}$ \\
\hline
\end{tabular}


Table 7 (continued)

\begin{tabular}{|c|c|c|c|c|c|c|c|c|}
\hline \multirow{3}{*}{$\frac{\text { Variables }}{\text { Activities }}$} & \multicolumn{4}{|c|}{ GENDER } & \multicolumn{4}{|c|}{ PARENTAL SES } \\
\hline & \multicolumn{2}{|c|}{1998 Cohort } & \multicolumn{2}{|c|}{2008 Cohort } & \multicolumn{2}{|c|}{1998 Cohort } & \multicolumn{2}{|c|}{2008 Cohort } \\
\hline & & & & & & & & \\
\hline Gaming & 0.83 & $0.89^{\mathrm{a}}$ & 0.88 & $0.80^{\mathrm{a}}$ & 0.87 & 0.86 & 0.85 & $0.83^{b}$ \\
\hline Media & 0.28 & 0.27 & 0.89 & $0.87^{a}$ & 0.27 & 0.28 & 0.90 & $0.87^{b}$ \\
\hline Socializing & 0.19 & $0.24^{\mathrm{a}}$ & 0.26 & $0.32^{\text {a }}$ & 0.20 & $0.22 \mathrm{~b}$ & 0.32 & $0.27^{b}$ \\
\hline Education & 0.53 & $0.59^{\mathrm{a}}$ & 0.17 & 0.18 & 0.53 & $0.58^{b}$ & 0.18 & $0.16^{b}$ \\
\hline Personal development & 0.51 & $0.46^{\mathrm{a}}$ & 0.58 & $0.52^{\text {a }}$ & 0.46 & $0.50^{b}$ & 0.55 & 0.55 \\
\hline Mobile phone ownership & 0.65 & 0.58 a & 0.79 & 0.77 & 0.53 & $0.68^{b}$ & 0.70 & $0.83 \mathrm{~b}$ \\
\hline Adult supervision & 0.65 & $0.69^{\mathrm{a}}$ & 0.52 & $0.55^{\text {a }}$ & 0.71 & $0.64^{b}$ & 0.52 & $0.55^{b}$ \\
\hline$N$ & 3195 & 3443 & 3195 & 3443 & 2785 & 3843 & 2851 & 3994 \\
\hline
\end{tabular}

Source: Growing Up in Ireland (GUI) Survey

a Indicates significant gender differences at the $95 \%$ level for the specific activity within the same cohort

$\mathrm{b}$ Indicates significant SES differences at the $95 \%$ level for the specific activity within the same cohort

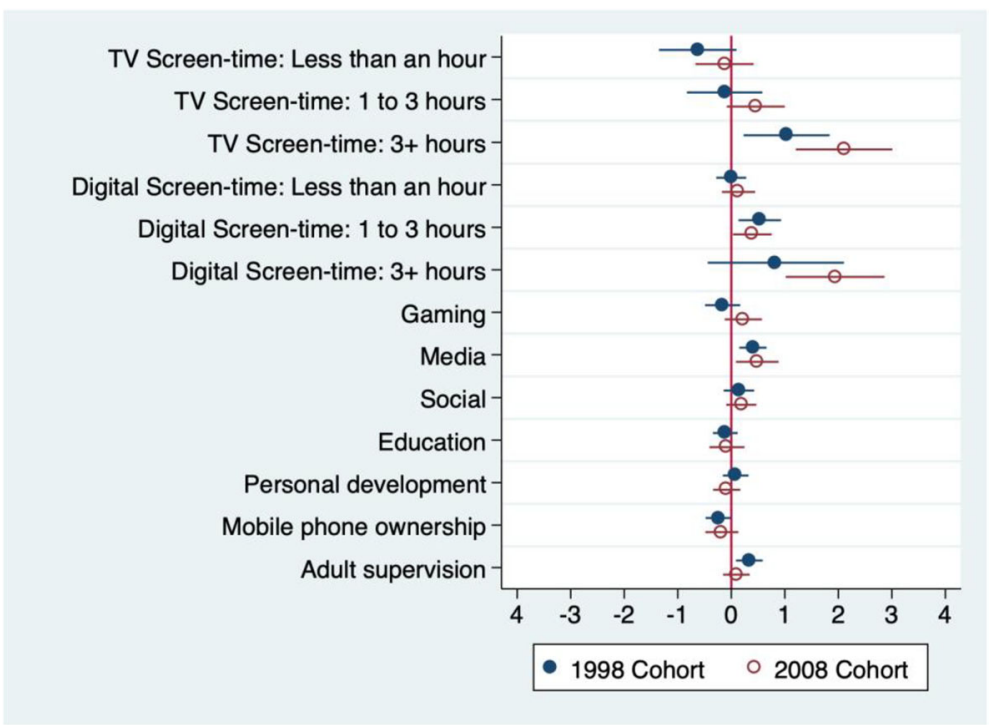

Fig. 4 Linear Regression Models. Child Socioemotional Problems (SDQ) by Cohort. Note: Regression coefficients from models of Table 3 (Column 2 and Column 3) for selected variables differentiating between the 1998 cohort $(\mathrm{N}=6628)$ and 2008 cohort $(\mathrm{N}=6575)$, including Confidence Intervals at the $95 \%$ level, and adjusting for all the study control variables 
Open Access This article is licensed under a Creative Commons Attribution 4.0 International License, which permits use, sharing, adaptation, distribution and reproduction in any medium or format, as long as you give appropriate credit to the original author(s) and the source, provide a link to the Creative Commons licence, and indicate if changes were made. The images or other third party material in this article are included in the article's Creative Commons licence, unless indicated otherwise in a credit line to the material. If material is not included in the article's Creative Commons licence and your intended use is not permitted by statutory regulation or exceeds the permitted use, you will need to obtain permission directly from the copyright holder. To view a copy of this licence, visit http://creativecommons.org/licenses/by/4.0/.

\section{References}

Babic, M., Smith, J., Morgan, P., Eather, N., Plotnikoff, R., \& Lubans, D. (2017). Longitudinal associations between changes in screen-time and mental health outcomes in adolescents. Mental Health and Physical Activity, 12, 124-131.

Baker, R., \& White, K. (2010). In their own words: Why teenagers don't use social networking sites. Cyberpsychology, Behavior and Social Networking, 14(6), 395-398.

Barker, V. (2009). Older adolescents' motivations for social network site use: The influence of gender, group identity, and collective self-esteem. Cyberpsychology \& Behavior, 12(2), 209-213.

Ben-Arieh, A., \& Ofir, A. (2002). Opinion, dialogue, review: Time for (more) time-use studies: Studying the daily activities of children. Childhood, 9(2), 225-248.

Bennett, S., Maton, K., \& Kervin, L. (2008). The 'digital natives' debate: A critical review of the evidence. British Journal of Educational Technology, 39(5), 775-786.

Berryman, C., Ferguson, C. J., \& Negy, C. (2018). Social media use and mental health among young adults. Psychiatric Quarterly, 89, 307-314.

Best, P., Manktelow, R., \& Taylor, B. (2014). Online communication, social media and adolescent wellbeing: A systematic narrative review. Children and Youth Services Review, 41, 27-36.

Blair, S., Claster, P., \& Claster, S. (2015). Technology and youth: Growing up in a digital world. Bingley: Emerald Group Publishing.

Bøe, T., Øverland, S., Lundervold, A., \& Hysing, M. (2012). Socioeconomic status and children's mental health: Results from the Bergen child study. Social Psychiatry Psychiatric Epidemiology, 47, 1557-1566.

Booker, C., Skew, A., Kelly, Y., \& Sacker, A. (2015). Media use, sports participation, and well-being in adolescence: Cross-sectional findings from the UK household longitudinal study. American Journal of Public Health, 105(1), 173-179.

Booker, C., Kelly, Y., \& Sacker, A. (2018). Gender differences in the associations between age trends of social media interaction and well-being among 10-15 year olds in the UK. BMC Public Health, 18, 321.

Brito, R., Dias, P., \& Oliveira, G. (2018). Young children, digital media and smart toys: How perceptions shape adoption and domestication. British Journal of Educational Technology, 49(5), 807-820.

Brooks, F., Chester, K., Smeeton, N., \& Spencer, N. (2016). Video gaming in adolescence: Factors associated with leisure time use. Journal of Youth Studies, 19(1), 36-54.

Bruggeman, H., Van Hiel, A., Van Hal, G., \& Van Dongen, S. (2019). Does the use of digital media affect psychological well-being? An empirical test among children aged 9 to 12. Computers in Human Behavior, 101, 104-113.

Camerini, A., Schulz, P. J., \& Jeannet, A. (2018). The social inequalities of Internet access, its use, and the impact on children's academic performance: Evidence from a longitudinal study in Switzerland. New Media \& Society, 20(7), 2489-2508.

Campbell, C., \& Pearlman, J. (2013). Period effects, cohort effects, and the narrowing gender wage gap. Social Science Research, 42(6), 1693-1711.

Campbell, W. K., Campbell, S. M., Siedor, L. E., \& Twenge, J. M. (2015). Generational differences are real and useful. Industrial and Organizational Psychology, 8(3), 324-408.

Cantillon, B., Chzhen, Y., Handa, S., \& Nolan, N. (Eds.). (2017). Children of austerity: Impact of the great recession on child poverty in rich countries. Oxford: Oxford University Press.

Casey, A., Layte, R., Lyons, S., \& Silles, M. (2012). Home computer use and academic performance of nineyear-olds. Oxford Review of Education, 38(5), 617-634.

Castellacci, F., \& Tveito, V. (2018). Internet use and well-being: A survey and a theoretical framework. Research Policy, 47, 308-325. 
Central Statistics Office. (2015). Census 2002: Principal socio-economic results. Dublin: Stationary Office.

Davis, K. (2012). Friendship 2.0: Adolescents' experiences of belonging and self-disclosure online. Journal of Adolescence, 35(6), 1527-1536.

Davis, E., Sawyer, M., Kai Lo, S., Priest, N., \& Wake, M. (2010). Socioeconomic risk factors for mental health problems in 4-5-year-old children: Australian population study. Academic Pediatrics, 10(1), 4147.

De Waal, E., \& Schoenbach, K. (2010). News sites' position in the mediascape: Uses, evaluations and media displacement effects over time. New Media \& Society, 12(3), 477-496.

Dempsey, S., Lyons, S., \& McCoy, S. (2019). Later is better: Mobile phone ownership and child academic development, evidence from a longitudinal study. Economics of Innovation and New Technology, 28, 798-815.

Fahy, A., Stansfeld, S., Smuk, M., et al. (2016). Longitudinal associations between cyberbullying involvement and adolescent mental health. Journal of Adolescent Health, 59(5), 502-509.

Fioravanti, G., Dèttore, D., \& Casale, S. (2012). Adolescent internet addiction: Testing the association between self-esteem, the perception of internet attributes, and preference for online social interactions. Cyberpsychology, Behavior and Social Networking, 15(6), 318-323.

Fomby, P., Goode, J. A., Truong-Vu, K. P., \& Mollborn, S. (2019). Adolescent technology, sleep, and physical activity time in two U.S. cohorts. Youth and Society, 1-25.

Fortunati, L., Taipale, S., \& de Luca, F. (2019). Digital generations, but not as we know them. Convergence, 25(1), 95-112.

Gentile, D., Coyne, S., \& Bricolo, F. (2013). Pathological technology addictions: What is scientifically known and what remains to be learned. In K.E. Dill (Ed.), Oxford library of psychology. The Oxford handbook of media psychology (pp 382-402). New York City: Oxford University Press.

George, M., Russell, M., Piontak, J., \& Odgers, C. (2018). Concurrent and subsequent associations between daily digital technology use and high-risk adolescents' mental health symptoms. Child Development, 89(1), 78-88.

Gershuny, J. (2003). Web use and net nerds: A neofunctionalist analysis of the impact of information Technology in the Home. Social Forces, 82(1), 141-168.

Goode, J. A., Fomby, P., Mollborn, S., \& Limburg, A. (2019). Children's technology time in two US cohorts. Child Indicators Research, 13, 1107-1132.

Goodman, A., \& Goodman, R. (2011). Population mean scores predict child mental disorder rate: Validating SDQ prevalence estimators in Britain. The Journal of Child Psychology and Psychiatry, 52(1), 100-108.

Gracia, P. (2015). Parent-child leisure activities and cultural capital in the United Kingdom: The gendered effects of education and social class. Social Science Research, 52(4), 290-302.

Gracia, P. (2020). Children's time use. In D. T. Cook (Ed.), The SAGE encyclopedia of children and childhood studies (pp. 504-506). London: Sage.

Gracia, P., \& Garcia-Roman, J. (2018). Child and adolescent developmental activities and time use in Spain: The gendered role of parents' work schedules and education levels. European Sociological Review., 34(5), 518-538.

Gracia, P., Garcia-Roman, J., Oinas, T., \& Anttila, T. (2019). Child and adolescent time use: A cross-national study. Journal of Marriage and Family., 82, 1304-1325. https://doi.org/10.1111/jomf.12626.

Gracia, P., Garcia-Roman, J., Oinas, T., \& Anttila, T. (2020). Do boys' and girls' daily activities differ? Crosscountry evidence. SocArXiv Papers. https://doi.org/10.31235/osf.io/nruq7.

Gross, E. F. (2009). Logging on, bouncing back: An experiential investigation of online communication following social exclusion. Developmental Psychology, 45, 1787-1793.

Holloway, D., Green, L., \& Stevenson, K. (2015). Digitods: Toddlers, touch screens and Australian family life. M/C Journal, $18(5)$.

Hope, S., Pearce, A., Whitehead, M., \& Law, C. (2014). Family employment and child socioemotional behaviour: Longitudinal findings from the UK millennium cohort study. Journal of Epidemiology and Community Health, 68(10), 950-957.

Hwang, J. M., Cheong, P. H., \& Feeley, T. H. (2009). Being young and feeling blue in Taiwan: Examining adolescent depressive mood and online and offline activities. New Media \&Society, 11(7), 1101-1121.

Jackson, L., FitzGerald, H., Zhao, Y., Kolenic, A., von Eye, A., \& Harold, R. (2008). Information Technology (IT) use and children's psychological well-being. Cyberpsychology \& Behavior, 11(6), 755-757.

Kelly, Y., Zilanawala, A., Booker, C., \& Sacker, A. (2018). Social media use and adolescent mental health: Findings from the UK millennium cohort study. EClinicalMedicine, 6, 59-68.

Klanšček, H. J., Žiberna, J., Korošec, A., Zurc, J., \& Albeht, T. (2014). Mental health inequalities in Slovenian 15 -year-old adolescents explained by personal social position and family socioeconomic status. International Journal for Equity in Health, 13(26), 26. 
Koenker, R., \& Hallock, K. F. (2001). Quantile regression. Journal of Economic Perspectives, 15(4), 143156.

Kross, E., Verduyn, P., Demiralp, E., Park, J., Lee, D. S., Lin, N., Shablack, H., Jonides, J., \& Ybarra, O. (2013). Facebook use predicts declines in subjective well-being in young adults. PLoS One, 8(8), 1-6.

Kucirnova, N., \& Sakr, M. (2015). Child-father creative text-making at home with crayons, iPad collage and PC. Thinking Skills and Creativity, 17, 59-63.

Leathers, H., Summers, S., \& Desollar, A. (2013). Toddlers on technology: A Parents' guide. Bloomington: AuthorHouse.

Lemola, S., Perkinson-Gloor, N., Brand, S., Dewald-Kaufmann, J., \& Grob, A. (2015). Adolescents' electronic media use at night, sleep disturbance, and depressive symptoms in the smartphone age. Journal of Youth \& Adolescence, 44, 405-418.

Leung, L. (2014). Predicting internet risks: A longitudinal panel study of gratifications-sought, internet addiction symptoms, and social media use among children and adolescents. Health Psychology and Behavioral Medicine: An Open Access Journal, 2(1), 424-439.

Li, C. (2013). Little's test of missing completely at random. The Stata Journal, 13(4), 795-809.

Liff, S., and Shepherd, A. (2004). An evolving gender digital divide? OII Internet Issue Brief, 2, 1-10.

Liu, M., Ming, Q., Yi, J., Wang, X., \& Yao, S. (2016). Screen time on school days and risks for psychiatric symptoms and self-harm in mainland Chinese adolescents. Frontiers in Psychology, 7(1), 1-11.

Livingstone, S., \& Helsper, E. (2007). Gradations in digital inclusion: Children, young people and the digital divide. New Media and Society, 9(4), 671-696.

Livingstone, S., \& Helsper, E. (2010). Balancing opportunities and risks in teenagers' use of the internet: The role of online skills and internet self-efficacy. New Media \& Society, 12(2), 309-329.

Livingstone, S., Mascheroni, G., \& Staksrud, E. (2018). European research on children's internet use: Assessing the past and anticipating the future. New Media and Society, 20(3), 1103-1122.

Mannheim, K. (1952). The sociological problem of generations. Essays in the Sociology of Knowledge, 276322 .

Mascheroni, G., \& Cuman, A. (2014). Net Children Go Mobile: Final report. Deliverables D6.4 \& D5.2. Milano: Educatt.

Mascheroni, G., \& Olafsson, K. (2016). The mobile internet: Access, use, opportunities and divides among European children. New Media \& Society, 18(8), 1657-1679.

Nikken, P., \& Opree, S. J. (2018). Guiding young children's digital media use: SES-differences in mediation concerns and competence. Journal of Child and Family Studies, 27, 1844-1857. https://doi.org/10.1007 /s10826-018-1018-3.

Noonan, K., Burns, R., \& Violato, M. (2018). Family income, maternal psychological distress and child socioemotional behaviour: Longitudinal findings from the UK millennium cohort study. SSM - Population Health, 4, 280-290.

O’Neill, B., \& Dinh, T. (2015). Net children go Mobile: Full findings from Ireland. Dublin: Dublin Institute of Technology.

O’Neill, B., Grehan, S., \& Ólafsson, K. (2011). Risks and safety for children on the internet: The Ireland report. LSE, London: EU Kids Online.

Orben, A., \& Przybylski, A. (2019a). The association between well-being and digital technology use. Nature Human Behaviour, 3(February), 173-182.

Orben, A., \& Przybylski, A. (2019b). Screens, teens, and psychological well-being: Evidence from three timeuse-diary studies. Psychological Science, 30, 682-696.

Orben, A., Dienlin, T., \& Przybylski, A. (2019). Reply to Foster and Jackson: Open scientific practices are the way forward for social media effects research. PNAS, 116(31), 15334-15335.

Ortega, F. B., Ruiz, J. R., Martinez-Gómez, D., De Henauw, S., et al. (2010). Sedentary patterns and media availability in European adolescents: The HELENA study. Preventive Medicine, 51(1), 50-55.

Pantic, I., Damjanovic, A., Todorovic, J., Topalovic, D., Bojovic-Jovic, D., Ristic, S., \& Pantic, S. (2012). Association between online social networking and depression in high school students: Behavioral physiology viewpoint. Psychiatria Danubina, 24(1), 90-93.

Parkes, A., Sweeting, H., Wight, D., \& Henderson, M. (2013). Do television and electronic games predict children's psychosocial adjustment? Longitudinal research using the UK millennium cohort study. Archives of Disease in Childhood, 98(5), 341-348.

Piotrowska, P., Stride, C., Croft, S., \& Rowe, R. (2015). Socioeconomic status and antisocial behaviour among children and adolescents: A systematic review and meta-analysis. Clinical Psychology Review, 35, 47-55. 
Przybylski, A. K., \& Weinstein, N. (2017). A large-scale test of the goldilocks hypothesis: Quantifying the relations between digital screen use and the mental well-being of adolescents. Psychological Science, 28(2), 204-215.

Quail, A., O’Reilly, C., Watson, D., McNamara, E., O’Mahony, D., and Murray, A. (2019) Growing up in Ireland: A summary guide to cohort ' 08 at 9 years. Available at: https://www.growingup. ie/pubs/Summary-Guide-Infant-Cohort-Wave-5.pdf.

Reinhard, E., Layte, R., McCrory, C., Panico, L., \& Avendano, M. (2018). The great recession and the health of young children: A fixed-effects analysis in Ireland. American Journal of Epidemiology, 187(7), 14381448 .

Selfhout, M., Branje, S., Delsing, M., ter Bogt, T., \& Meeus, W. (2009). Different types of internet use, depression, and social anxiety: The role of perceived friendship quality. Journal of Adolescence, 32(4), 819-833.

Shu, X., \& Meagher, K. (2018). Beyond the Stalled Gender Revolution: Historical and Cohort Dynamics in Gender Attitudes from 1977 to 2016. Social Forces, 96(3), 1243-1274.

Stiglic, N., \& Viner, R. (2019). Effects of screentime on the health and well-being of children and adolescents: A systematic review of reviews. BMJ Open, 9(1), 1-15.

The Children's Society. (2015). The good childhood report 2015. London: The Children's Society.

Twenge, J., Joiner, T., Rogers, M., \& Martin, G. (2018). Increases in depressive symptoms, suicide-related outcomes, and suicide rates among U.S. adolescents after 2010 and links to increased new media screen time. Clinical Psychological Science, 6(1), 3-17.

Valkenburg, P. M., \& Piotrowski, J. T. (2017). Plugged in: How media attract and affect youth. New Haven: Yale University Press.

van den Eijnden, R., Meerkerk, G., Vermulst, A., Spijkerman, R., \& Engels, R. (2008). Online communication, compulsive internet use, and psychosocial well- being among adolescents: A longitudinal study. Developmental Psychology, 44(3), 655-665.

van der Aa, N., Overbeek, G., Engels, R., Scholte, R., Meerkerk, G., \& van den Eijnden, R. (2009). Daily and compulsive internet use and well-being in adolescence: A diathesis-stress model based on big five personality traits. Journal of Youth and Adolescence, 38(765).

van Deursen, A., \& van Dijk, J. (2014). The digital divide shifts to differences in usage. New Media \& Society, 16(3), 507-526.

Verduyn, P., Jonides, J., \& Kross, E. (2017). Do social network sites enhance or undermine subjective wellbeing? A Critical Review. Social Issues and Policy Review, 11(1), 274-302.

Vilhelmson, B., Elldér, E., \& Thulin, E. (2018). What did we do when the internet wasn't around? Variation in free-time activities among three young-adult cohorts from 1990/1991, 2000/2001, and 2010/2011. New Media and Society, 20(8), 2898-2916.

Wight, V., Price, J., Bianchi, S., \& Hunt, B. (2009). The time use of teenagers. Social Science Research, 38(4), 792-809.

Williams, A., \& Merten, M. (2008). A review of online social networking profiles by adolescents. Implications for future research and intervention. Adolescence, 32(170), 253-273.

Williams, J., Greene, S., Doyle, E., Harris, E., Layte, R., McCoy, S., ... \& Thornton, M. (2009). Growing up in Ireland national longitudinal study of children. The lives of 9 year olds. Dublin: The Stationary Office.

Yang, Y. (2008). Social inequalities in happiness in the United States, 1972 to 2004: An age- period-cohort analysis. American Sociological Review, 73, 204-226.

Publisher's Note Springer Nature remains neutral with regard to jurisdictional claims in published maps and institutional affiliations. 